\title{
Suppressor mutations in Mecp2-null mice implicate the DNA damage response in Rett syndrome pathology
}

\author{
Adebola Enikanolaiye, ${ }^{1,10}$ Julie Ruston, ${ }^{1,10}$ Rong Zeng, ${ }^{1,10}$ Christine Taylor, ${ }^{1}$ \\ Marijke Schrock, ${ }^{2}$ Christie M. Buchovecky, ${ }^{2,11}$ Jay Shendure, ${ }^{3,4,5,6}$ Elif Acar, ${ }^{7,8}$ \\ and Monica J. Justice ${ }^{1,2,7,9}$
}

${ }^{1}$ Program in Genetics and Genome Biology, The Hospital for Sick Children, Toronto, Ontario, M5G 0A4, Canada; ${ }^{2}$ Department of Molecular and Human Genetics, Baylor College of Medicine, Houston, Texas 77030, USA; ${ }^{3}$ Department of Genome Sciences, University of Washington, Seattle, Washington 98195, USA; ${ }^{4}$ Brotman Baty Institute for Precision Medicine, Seattle, Washington 98195, USA; ${ }^{5}$ Allen Discovery Center for Cell Lineage Tracing, Seattle, Washington 98195, USA; ${ }^{6}$ Howard Hughes Medical Institute, Seattle, Washington 98195, USA; ${ }^{7}$ The Centre for Phenogenomics, Toronto, Ontario, M5T 3H7, Canada; ${ }^{8}$ Department of Statistics, University of Manitoba, Winnipeg, Manitoba, R3T 2N2, Canada; ${ }^{9}$ Department of Molecular Genetics, University of Toronto, Toronto, Ontario, M5S 1A8, Canada

\begin{abstract}
Mutations in X-linked methyl-CpG-binding protein 2 (MECP2) cause Rett syndrome (RTT). To identify functional pathways that could inform therapeutic entry points, we carried out a genetic screen for secondary mutations that improved phenotypes in Mecp2/Y mice after mutagenesis with $\mathrm{N}$-ethyl- $N$-nitrosourea (ENU). Here, we report the isolation of 106 founder animals that show suppression of Mecp2-null traits from screening $3177 \mathrm{Mecp} 2 / Y$ genomes. Whole-exome sequencing, genetic crosses, and association analysis identified 22 candidate genes. Additional lesions in these candidate genes or pathway components associate variant alleles with phenotypic improvement in 30 lines. A network analysis shows that $63 \%$ of the genes cluster into the functional categories of transcriptional repression, chromatin modification, or DNA repair, delineating a pathway relationship with MECP2. Many mutations lie in genes that modulate synaptic signaling or lipid homeostasis. Mutations in genes that function in the DNA damage response (DDR) also improve phenotypes in Mecp2/Y mice. Association analysis was successful in resolving combinatorial effects of multiple loci. One line, which carries a suppressor mutation in a gene required for cholesterol synthesis, Sqle, carries a second mutation in retinoblastoma binding protein 8 , endonuclease (Rbbp8, also known as CtIP), which regulates a DDR choice in double-stranded break (DSB) repair. Cells from Mecp2/Y mice have increased DSBs, so this finding suggests that the balance between homology-directed repair and nonhomologous end joining is important for neuronal cells. In this and other lines, two suppressor mutations confer greater improvement than one alone, suggesting that combination therapies could be effective in RTT.
\end{abstract}

[Supplemental material is available for this article.]

Mouse genetics is a powerful tool to identify molecular mechanisms that are important for disease suppression. By using a modifier screen, a dominant mutation can be isolated by its ability to alter the presentation of a recessive or dominant trait to discover genes that act in a given developmental or biochemical pathway. Modifier screens have been rare in the mouse; however, using massively parallel sequencing technologies, candidate mutations can now be efficiently identified without extensive breeding and mapping. Mutagenesis screens that focus on disease suppression may identify unrecognized pathways of pathogenesis as alternative therapeutic entry points.

Rett syndrome (RTT) is a prototype disease for which a modifier screen would be beneficial and representative for other diseases. RTT is a nearly monogenic disorder with $>95 \%$ of patients carrying mutations in methyl-CpG-binding protein 2 (MECP2), a gene not present in invertebrates. MECP2 is central to neurological function

\footnotetext{
${ }^{10}$ These authors contributed equally to this work. 11 Present address: Division of Reproductive Genomics, SEMA4, New York, NY 10029, USA

Corresponding author: monica.justice@sickkids.ca

Article published online before print. Article, supplemental material, and publication date are at http://www.genome.org/cgi/doi/10.1101/gr.258400.119. Freely available online through the Genome Research Open Access option.
}

and is associated with other diseases, including intellectual disabilities, autism, neuropsychiatric disorders, and lupus erythematosus (Neul and Zoghbi 2004; Bienvenu and Chelly 2006). The type of MECP2 mutation does not always correlate with disease severity, in part, because of skewing of X Chromosome inactivation in heterozygous females (Shahbazian et al. 2002). Hemizygous males with truncating or loss of function mutations in MECP2 usually die by two years of age (Bienvenu and Chelly 2006).

Mouse models recapitulate many of the pathologic features of RTT and are crucial for understanding the molecular and cellular basis (Chen et al. 2001; Guy et al. 2001). Male mice that lack Mecp2 are normal through three weeks of age, but they develop hypoactivity, limb clasping, tremors, and abnormal breathing as early as four weeks, depending upon the allele and the genetic background (Katz et al. 2012). The symptoms become progressively worse, leading to their death at 6-12 wk. RTT has historically been considered a neurological disease (Jellinger and Seitelberger 1986). MECP2 is expressed at near histone levels in neurons, and neurons of Mecp2/Y mice show a number of deficits, including delayed transition into mature stages, altered expression of

(C) 2020 Enikanolaiye et al. This article, published in Genome Research, is available under a Creative Commons License (Attribution 4.0 International), as described at http://creativecommons.org/licenses/by/4.0/. 
presynaptic proteins, and reduced dendritic spine density (Xu et al. 2014). However, MECP2's expression outside the nervous system leads to a number of systemic issues, including metabolic syndrome (Kyle et al. 2016, 2018; Ross et al. 2016).

Multiallelic contributions or environmental effects may cause the wide degree of phenotypic variation that is common to many human diseases (Enikanolaiye and Justice 2019). Rare familial cases of RTT suggest that genetic modification can alter the severity of symptoms (Ravn et al. 2011; Grillo et al. 2012), but for any rare disorder, finding the molecular basis for phenotypic modification in humans is daunting. Identifying genes that when mutated ameliorate the phenotype in a mouse model would help to focus efforts toward understanding the functions of MECP2 and how the disease ensues upon its loss. Further, identifying the genes that improve the RTT-like phenotype in mice may allow for the discovery of pathways that inform therapeutic strategies in humans. In a preliminary dominant suppressor mutagenesis screen using the supermutagen $\mathrm{N}$-ethyl- $\mathrm{N}$-nitrosourea (ENU), we isolated five modifier loci, named suppressor of methyl CpG binding protein (Sum) 1-5, which suppress or ameliorate the phenotype in Mecp2/Y male mice (Buchovecky et al. 2013). We previously reported that the lesion responsible for disease amelioration at the Sum $3^{\text {Jus }}$ locus is a stop codon mutation in a rate-limiting enzyme in cholesterol biosynthesis, squalene epoxidase (Sqle). This finding led to the discovery that cholesterol and lipid homeostasis is perturbed in Mecp2 male and female mice, and that statin drugs ameliorate symptoms as well (Buchovecky et al. 2013). This discovery suggested that finding additional modifiers would lead to a better understanding of Mecp2's functions and how its mutation could lead to pathological changes. Our overarching goal was to identify a large number of suppressors such that a list of potential therapeutic targets could be developed for RTT.

\section{Results}

Two suppressor screens produce 106 founders with trait improvement

ENU-treated C57BL/6J males were bred to female 129.Mecp $2^{\text {tm1.1Bird/+ }}$ mice (Fig. 1A). Male offspring in the first generation (N1), asymptomatic at weaning, were genotyped for presence of mutant Mecp2 and examined for amelioration of disease phenotypes by a dominant mutation. In total, 3177 relevant gametes were screened for phenotype improvement. The preliminary screen 1 produced 2963 animals of which 679 were Mecp2/Y (Fig. $1 \mathrm{~A}$, gray; Buchovecky et al. 2013). This number is close to one genome's equivalent, because the mutation rate for the $3 \times 100 \mathrm{mg} /$ $\mathrm{kg}$ dose of ENU is about one new mutation per gene in every 655 gametes screened (Hitotsumachi et al. 1985). In screen 1, 10 lines showing suppression of traits were identified, but only six of these bred naturally and one (1527) was reconstituted by in vitro fertilization (IVF) of fresh sperm. A scoring system was used to individually assess limb clasping, tremors, body weight, and activity. In general, improvement of these scores indicated improved longevity as evidenced by the long lifetime of the founders and their offspring (Buchovecky et al. 2013).

In screen 2, an additional 10,069 animals, of which 2498 were Mecp2/Y, produced 96 additional N1 founder males that showed suppression of one or more traits. In screen 2, sperm from each founder was frozen, and of 23 lines mated, nine bred naturally before they were sacrificed, whereas 14 were reconstituted using IVF of frozen sperm. In screen 2, all N1 mice were evaluated weekly

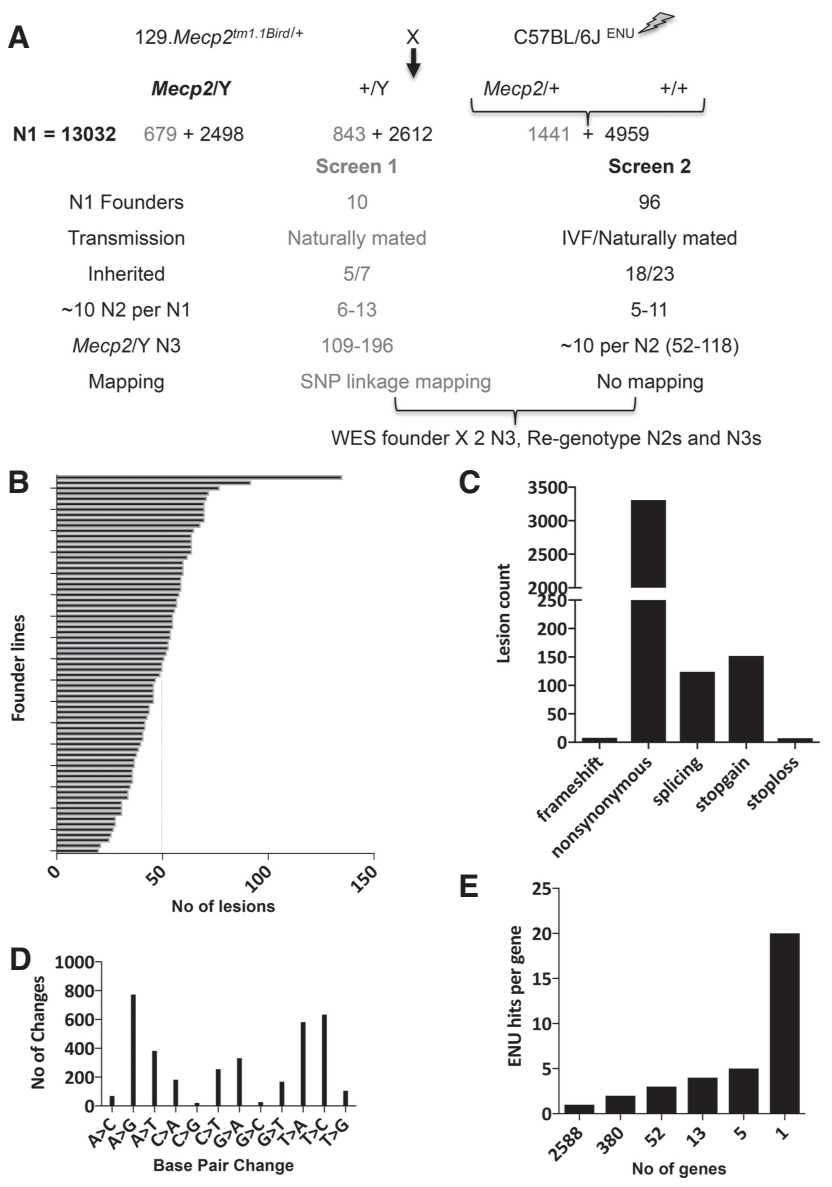

Figure 1. Overview of two dominant suppressor ENU mutagenesis screens in a Mecp $2^{\text {tm1.1Bird }}$ mouse model. $(A)$ Male C57BL/6J male mice were treated with ENU and mated to 129. Mecp $2^{\text {tm } 1.1 B i r d /+}$ females. Numbers obtained from screen 1, already published, are in gray, and screen 2 in black. A subset of N1 male founder mice (N1) carrying the mutant Mecp2 allele and showing suppression of disease phenotypes were bred (naturally or by IVF) for inheritance. N2 offspring were mated to 129.Mecp $2^{\text {tm 1.1 Bird/+ }}$ females or $129 \mathrm{S6} / \mathrm{SvEvTac}$ males to generate N3s, of which DNAs from at least two animals from different N2 families that showed trait improvement were whole-exome sequenced (WES). N3 offspring were genotyped to analyze for linkage or association. $(B)$ The WES was analyzed for 71 founder lines, producing 3601 potentially causative variants. Variants ranged in number from 20 to 135 , with a mean of 50. (C) The types of ENU-induced lesions generated were mostly nonsynonymous missense mutations $(3310,92 \%)$, followed by nonsense mutations (152, 4\%) and splicing mutations (124, 3\%). Frameshift mutations or the loss of a STOP codon accounted for the remainder (1\%). (D) The most common types of mutations induced by ENU were A to $\mathrm{G}$ and $\mathrm{T}$ to $\mathrm{C}$ transition mutations ( $22 \%$ and $18 \%$, respectively), closely followed by transversions (A to $\mathrm{T}[11 \%]$ and $\mathrm{T}$ to $\mathrm{A}[16 \%]$ ), whereas the fewest were $\mathrm{C}$ to $\mathrm{G}$ and $\mathrm{G}$ to $\mathrm{C}$ transversions $(<1 \%)$. $(E)$ The majority of genes with new ENU-induced lesions were unique, with 2588 genes carrying only one mutation. A single gene, titin (Ttn), had 20 alleles.

starting at P35 for four subjective health parameters that have previously been noted in Mecp2/Y mice (Guy et al. 2001): hindlimb clasping, tremors, activity, and general body condition. Muscle tone was also assessed, because it was also an important indicator of health. Each subjective parameter was scored out of 2, whereby 0 indicated the health trait was equivalent to wild type, 1 if intermediate, or 2 if severe. Body weights were also obtained weekly and were scored 0 if $<29 \mathrm{~g}, 1$ if between 30 and $34 \mathrm{~g}$, and 2 if $>35 \mathrm{~g}$. These five subjective health parameters and quantitative 
parameter body weight were totaled to obtain a score out of 12 . In screen 2, animals were classified as improved if their summed health score totaled $<8$ at 8 wk of age, and they were maintained generally until 12-14 wk, when they were sacrificed for sperm cryopreservation. N3 animals were evaluated using the same criteria. The Mecp2/Y animals from the strains maintained at the two institutions had different life spans, possibly owing to differing pathogen status. Therefore, Mecp $2 / Y$ animals from screen 1 were classified improved if they lived $\geq 14 \mathrm{wk}$, while those from screen 2 were classified improved if they lived $\geq 10 \mathrm{wk}$ and had improved scores on assessed health traits.

\section{Whole-exome sequencing identifies candidate genes in founder males}

When the first modifiers were isolated in screen 1, WES was not yet available, so the first line was sequenced by custom capture resequencing of a mapped region (line 352). WES was carried out on lines $856,895,1395$, and 1527 , but the sequence was analyzed only in the regions with positive LOD scores obtained by mapping, and only one candidate gene, Sqle, from line 895 was reported (Buchovecky et al. 2013). The WES of 69 of the founder N1 males from the second screen was analyzed for all potential contributing mutations throughout the genome (Supplemental Table S1). Naturally occurring single-nucleotide polymorphisms (SNPs) that were specific to the $129 \mathrm{~S} 6 / \mathrm{SvEv}$ and C57BL/6J strains were filtered by comparing with parental and all sequenced founder male genomes, and variants predicted to be tolerated were excluded. The remaining potentially causative 3601 variants ranged in number from 20 to 135 in each N1 founder male, with a mean of 50 (Fig. $1 \mathrm{~B})$. These variants were largely nonsynonymous missense mutations (92\%) (Fig. 1C), which were primarily transition mutations (A to $\mathrm{G}$ and $\mathrm{T}$ to $\mathrm{C}$ ) (Fig. 1D). Each of 2588 genes had only one allele found in the $\mathrm{N} 1$ males, each of 380 genes had different alleles in two lines, 52 genes had three alleles, 13 genes had four, five genes had five, and a single large gene, titin (Ttn), had 20 alleles (Fig. 1E).

\section{Confirming the candidate lesions shows complex inheritance of traits}

The inheritance of traits was determined by mating $30 \mathrm{~N} 1$ founders from both screens (seven from screen 1 and 23 from screen 2) to $129 . \mathrm{Mecp}^{1+}$ females. Their $\mathrm{N} 2$ female offspring, carrying the Mecp2 mutation inherited from their father, were mated again to $129 \mathrm{~S} 6 / \mathrm{SvEvTac}$ males, whereas N2 male offspring were mated to 129.Mecp $2^{/+}$females. In screen 1 , each line was mapped to narrow the suppressor locus to a chromosomal location using SNP panels before sequencing (Neuhaus and Beier 1998; Moran et al. 2006). In screen 2, SNPs were not used for mapping. When possible, up to 10 N2 offspring from each family were mated to produce approximately 10 Mecp2/Y N3 offspring, which were assessed for phenotype and aged. If the modifier was inherited in a Mendelian fashion, $50 \%$ of the N2 animals should have inherited the trait and $50 \%$ should pass it on to their N3 offspring; thus, only $25 \%$ of the total N3 offspring are expected to inherit the suppressor trait (Table 1). Of 30 lines, 23 showed evidence for inheritance of disease improvement (Supplemental Table S2). Nineteen of the 23 lines segregated modifier loci in a non-Mendelian fashion, suggesting involvement of more than one locus (Table 1). In lines 856 and 895 , the pattern of inheritance suggested that either locus conferred improvement, whereas the inheritance of both loci suggested additive health improvement. In contrast, although all families in line 520 had at least one animal with trait improvement, none showed greatly improved health scores, suggesting that the two loci may have influenced health traits independently. Seven lines, 137, 591, 722, 933_15N, A_87N, A_120N, and A_134L, were not solved because so few Mecp2/Y N3 animals showed trait improvement (fewer than eight), possibly because two or more loci must be inherited together to see an effect. It is also possible that a genetic combination resulted in decreased health or longevity, rather than improvement.

To identify candidate genes in screen 2 , the exome from a minimum of two N3 offspring that showed the largest degree of improvement and were from different N2 parents was also sequenced. Lesions that occurred in the $\mathrm{N} 1$ founder and these two offspring were regenotyped in individuals from families that inherited trait improvement (Fig. 1A; Supplemental Table S2). Common SNPs identified in WES were used to genotype N3 animals to confirm the location after candidate loci were identified.

Statistical analysis of candidate genes shows support for a solution in 13/23 lines (Tables 1, 2; Supplemental Table S3). Within these 13 lines, 22 genes are supported by association analysis as candidates for suppression of a variety of traits. Eight additional lines carry alleles of these 22 candidate genes, and 11 lines carry mutations in a related pathway member or Mecp 2 corepressor complex member. Some lines carry multiple associative mutations, thus, candidate genes have been identified in 30 of the lines (Tables 1,2). The screen 2 loci that are supported by mating and association analysis are named Sum 6-21 (Table 1). Candidate genes are identified for two of the lines from screen 1 (Prdm15 $5^{\text {Sum1-Jus }}$ and $Z z z 3^{\text {Sum2-Jus }}$, and a second suppressor was found in line 895 from screen $1\left(R b b p 8^{\text {Sum6-Jus }}\right)$.

\section{Candidate genes fall into similar functional pathways}

Genes with supported or pathway lesions were integrated into biological networks using Cytoscape (v3.7) (Shannon et al. 2003) and its accompanying applications GeneMANIA (v3.5.1) (WardeFarley et al. 2010) and clusterMaker (1.3.1) (Morris et al. 2011). A functional enrichment map (network) generated by coexpression, shared protein domains, physical interactions or predictions was further clustered into biological pathways, confirming that most of the genes fall into three major pathways; lipid homeostasis, synaptic function, and DNA damage (Fig. 2). Gene Ontology (GO) analysis revealed that the top 16 enriched terms in this network included MECP2-associated biological processes involved in transcriptional corepressor activity and chromatin-associated functions. However, it also revealed novel GO terms such as DNA recombination, double-strand break repair, and regulation of DNA metabolic processes. Thus $20 / 32$ or $63 \%$ of the genes cluster into the general category of "Regulation of DNA Activity," which is expected for a functional relationship with MECP2. The genes with unknown function (Clint1, Dennd $4 a$ ) fall outside the functional pathways.

\section{Chromatin structure and transcriptional regulation}

Several candidate genes are predicted to alter chromatin structure: These include PR domain containing 15 (Prdm15), zinc finger ZZ domain containing 3 (Zzz3), and lysine (K)-specific demethylase $4 \mathrm{~A}(K d m 4 a)$. The PR domain proteins, many of which have histone methyltransferase activity and others that recruit methyltransferases to DNA, play roles as molecular switches in many developmental processes (Fog et al. 2012; Hohenauer and Moore 2012; Mzoughi et al. 2017). ZZZ3 is a part of the Ada-Two-A-containing (ATAC) histone acetyltransferase complex, which widely regulates

\section{Genome Research}

www.genome.org 
Table 1. Assessment of Mendelian inheritance of suppressor loci

\begin{tabular}{|c|c|c|c|c|c|c|c|}
\hline \multirow{2}{*}{$\frac{\text { Line }}{352^{a, b}}$} & \multicolumn{2}{|c|}{$\begin{array}{l}\text { Families with } \\
\text { improvement }\end{array}$} & \multicolumn{2}{|c|}{$\begin{array}{c}\text { Number of } \mathrm{N} 3 \\
\text { Mecp/Y improved/ } \\
\text { total }\end{array}$} & \multirow{2}{*}{$\begin{array}{c}\text { Inheritance }(\boldsymbol{P} \text {-value }) \\
<0.001\end{array}$} & \multirow{2}{*}{$\frac{\text { Solved }}{\text { Prdm15 }}$} & \multirow{2}{*}{$\begin{array}{c}\text { MGI: ID } \\
\text { MGI:5489912 }\end{array}$} \\
\hline & $6 / 6$ & 1.00 & $36 / 129$ & 0.28 & & & \\
\hline $856^{a, b}$ & $10 / 10$ & 1.00 & $76 / 165$ & 0.46 & 0.003 & Zzz3 $3^{\text {Sum2-Jus }}$ & MGI:5489913 \\
\hline $895^{a, b}$ & $8 / 9$ & 0.89 & $32 / 109$ & 0.29 & $<0.001$ & $\begin{array}{l}\text { Sqle } e^{\text {Sum3-Jus }} \\
\text { Rbbp } 8^{\text {Sum6-Jus }}\end{array}$ & $\begin{array}{l}\text { MGI:5489914 } \\
\text { MGI:6367664 }\end{array}$ \\
\hline 520 & $8 / 8$ & 1.00 & 19/116 & 0.16 & $<0.001$ & $\begin{array}{l}\text { Cd22 } 2^{\text {Sum7-Jus }} \\
\text { Clint } 1^{\text {Sum7i-jus }} \\
\text { Kdm } 4 a^{\text {Sum8-Jus }}\end{array}$ & $\begin{array}{l}\text { MGI:6367718 } \\
\text { MGI:6367719 } \\
\text { MGI:6367720 }\end{array}$ \\
\hline $4654^{a}$ & $5 / 9$ & 0.56 & $8 / 81$ & 0.10 & $<0.001$ & $\begin{array}{l}\text { Tm7sf2 } 2^{\text {Sum 9-jus }} \\
\text { Dennd } 4 a^{\text {Sum 9i-jus }} \\
\text { Gtf3c5 } 5^{\text {Sum10-Jus }}\end{array}$ & $\begin{array}{l}\text { MGl:6367721 } \\
\text { MGl:6367722 } \\
\text { MGl:6367723 }\end{array}$ \\
\hline $4751^{a}$ & $5 / 6$ & 0.83 & $13 / 81$ & 0.16 & $<0.001$ & $\begin{array}{l}\text { Arhgef15 } 5^{\text {Sum11-Jus }} \\
\text { Spin1 } 1^{\text {Sum12-Jus }}\end{array}$ & $\begin{array}{l}\text { MGI:6367724 } \\
\text { MGI:6367725 }\end{array}$ \\
\hline $4799^{a}$ & $4 / 7$ & 0.57 & $8 / 70$ & 0.11 & $<0.001$ & $\begin{array}{l}\text { Aacs sum13-Jus } \\
\text { Atp8a1 Sum14-Jus }\end{array}$ & $\begin{array}{l}\text { MGI:6367726 } \\
\text { MGI:6367727 }\end{array}$ \\
\hline 918_15 $L^{\mathrm{a}}$ & $3 / 6$ & 0.50 & $7 / 60$ & 0.12 & $<0.001$ & Celsr3 $3^{\text {Sum 15-Jus }}$ & MGI:6367728 \\
\hline J_57L & $7 / 9$ & 0.78 & $18 / 108$ & 0.17 & $<0.001$ & $\begin{array}{l}\text { Hen } 2^{\text {Sum16-Jus }} \\
\text { Apoa5 } 5^{\text {Sum17-Jus }}\end{array}$ & $\begin{array}{l}\text { MGI:6367729 } \\
\text { MGI:6367730 }\end{array}$ \\
\hline $\begin{array}{l}\text { A_27R } \\
\text { A_333N }\end{array}$ & $\begin{array}{l}3 / 10 \\
3 / 8\end{array}$ & $\begin{array}{l}0.30 \\
0.38\end{array}$ & $\begin{array}{l}8 / 103 \\
9 / 62\end{array}$ & $\begin{array}{l}0.08 \\
0.15\end{array}$ & $\begin{array}{r}<0.001 \\
0.009\end{array}$ & $\begin{array}{l}\text { Tet } 1^{\text {Sum 18-Jus }} \\
\text { Fan1 }\end{array}$ & $\begin{array}{l}\text { MGI:6367732 } \\
\text { MGI:6367733 }\end{array}$ \\
\hline M_199LL $^{\text {a }}$ & $4 / 5$ & 0.80 & $9 / 52$ & 0.17 & 0.002 & $\begin{array}{l}\text { Birc6 } 6^{\text {Sum20-Jus }} \\
\text { Dbnl }\end{array}$ & $\begin{array}{l}\text { MGI:6367734 } \\
\text { MGI:6367735 }\end{array}$ \\
\hline M_333R ${ }^{\mathrm{a}}$ & $5 / 6$ & 0.83 & $10 / 88$ & 0.11 & $<0.001$ & Zbtb4 $1^{\text {Sum21-Jus }}$ & MGI:6367737 \\
\hline $1395^{a, b}$ & $6 / 6$ & 1.00 & 70/196 & 0.36 & $<0.001$ & Chr 7: Sum4 $4^{\text {M1/us }}$ & MGI:5489915 \\
\hline $1527^{b}$ & $13 / 14$ & 0.93 & $61 / 190$ & 0.32 & $<0.001$ & Sum5 $5^{\text {M1jus }}$ & MGI:5489916 \\
\hline $136^{\mathrm{a}}$ & $7 / 11$ & 0.64 & $12 / 104$ & 0.12 & $<0.001$ & Tet1 ${ }^{\text {Sum 18-2Jus }}$ & MGI:6367738 \\
\hline $137^{\mathrm{a}}$ & $7 / 10$ & 0.70 & $7 / 101$ & 0.07 & $<0.001$ & & \\
\hline 591 & $7 / 9$ & 0.78 & $7 / 114$ & 0.06 & $<0.001$ & Tet ${ }^{\text {Sum 18-3/us }}$ & MGI:6367739 \\
\hline 722 & $4 / 10$ & 0.40 & $8 / 102$ & 0.08 & $<0.001$ & & \\
\hline 933_15N & $4 / 10$ & 0.40 & $5 / 118$ & 0.04 & $<0.001$ & & \\
\hline A_87̄N & $4 / 9$ & 0.44 & $8 / 95$ & 0.08 & $<0.001$ & & \\
\hline A_120N & $3 / 7$ & 0.43 & $8 / 70$ & 0.11 & 0.002 & & \\
\hline A_134L ${ }^{a}$ & $3 / 5$ & 0.60 & $8 / 84$ & 0.10 & $<0.001$ & & \\
\hline A_230RR & NM & & & & & Arhgef1 $5^{\text {Sum11-2Jus }}$ & MGI:6367741 \\
\hline 604 & NM & & & & & Celsr3 $3^{\text {Sum 15-2Jus }}$ & MGI:6367747 \\
\hline A_347N & NM & & & & & Celsr $3^{\text {Sum15-3/us }}$ & MGI:6367758 \\
\hline A_83L & NM & & & & & Birc6 $6^{\text {Sum 20-2Jus }}$ & MGI:6367762 \\
\hline $6 \overline{2} 0$ & NM & & & & & $\begin{array}{l}\text { Birc6 }^{\text {Sum20-3/us }} \\
\text { Ncor1 } \\
\text { Brca1 }\end{array}$ & MGI:6367772 \\
\hline S_165N & NM & & & & & Ncor1 & \\
\hline A_189N & NM & & & & & Brca1 & \\
\hline J_157N & NM & & & & & Tbl1 $\times r 1$ & \\
\hline J_136N & NM & & & & & Zbtb4 $1^{\text {Sum21-2Jus }}$ & MGI:6367777 \\
\hline M_420L & NM & & & & & Mre11a & \\
\hline M_79N & NM & & & & & Rad50 & \\
\hline A_173N & NM & & & & & Brca2 & \\
\hline 920_39R & NM & & & & & Сур46а1 & \\
\hline $463 \overline{3}$ & NM & & & & & Rcor1 & \\
\hline 272 & NM & & & & & $\sin 3 a$ & \\
\hline
\end{tabular}

Complex versus Mendelian inheritance was assessed from breeding data as described in Methods (Supplemental Table S2). The second column in "Families with Improvement" and in "Number of N3 Mecp2/Y improved/total" represents the ratio of the numbers in the first column. Column 4 presents the $P$-value of the Fisher's exact test for testing the Mendelian hypothesis calculated based on $10^{6}$ Monte Carlo simulations. A $P$-value $<0.001$ provides sufficient evidence to reject the Mendelian hypothesis. Bold indicates lines in which a candidate gene was associated with one or more improved traits. Loci that had an effect only in the presence of another supported suppressor locus are named interacting loci (i).

aLine mated naturally, (NM) not mated.

bines from screen 1.

gene expression (Mi et al. 2018). KDM4A is important for the structure of heterochromatin during embryonic development, and it influences neuropathic pain through brain derived neurotrophic factor (BDNF) expression (Sankar et al. 2017; Zhou et al. 2017). The corepressors Ncor1, transducin (beta)-like 1X-linked receptor 1(Tbl1xr1), Rcor1, and $\operatorname{Sin} 3 a$ are transcriptional repressors that act with MECP2, yet missense mutations in these genes occurred in lines that were not mated, so they are included in Table 2 but are not given Sum designations.

\section{Lipid homeostasis}

Four mutations (Aacs, Apoa5, Atp8a1, Tm7sf2) support previous publications that lipid metabolism is a primary pathway for pathogenesis (Buchovecky et al. 2013; Justice et al. 2013; Segatto et al. 2014; Kyle et al. 2016). The founding lesion in this pathway occurred in Sqle, a rate-limiting enzyme in cholesterol synthesis. MECP2 anchors a protein complex containing the master metabolic regulator nuclear receptor co-repressor 1 (NCOR1) to DNA. 


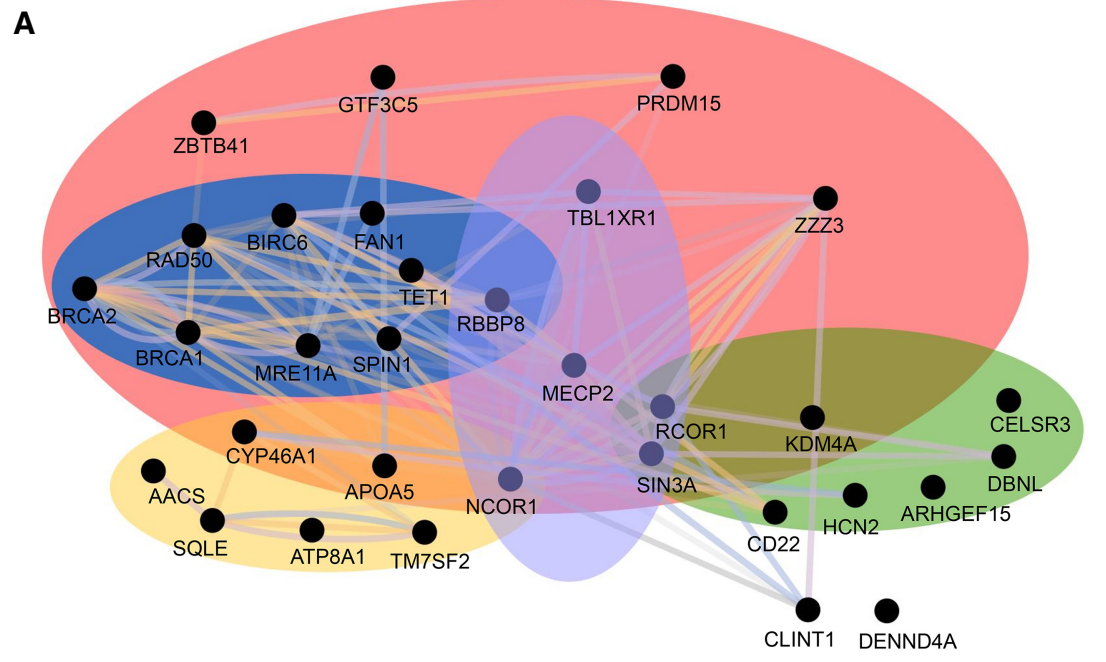

B

\begin{tabular}{lllccc} 
GO ID & \multicolumn{1}{c}{$\begin{array}{c}\text { Description } \\
\text { GO:0006302 }\end{array}$} & $\begin{array}{c}\text { Genes in } \\
\text { q-value }\end{array}$ & $\begin{array}{c}\text { Genes in } \\
\text { Network }\end{array}$ & $\begin{array}{c}\text { Percentage } \\
\text { Genome } \\
\text { Coverage }\end{array}$ \\
GO:0017053 & transcriptional repressor complex & 0.00033 & 6 & 113 & 5 \\
GO:1902275 & regulation of chromatin organization & 0.00053 & 5 & 67 & 7 \\
GO:0035067 & negative regulation of histone acetylation & 0.00194 & 5 & 94 & 5 \\
GO:1901984 & negative regulation of protein acetylation & 0.00195 & 3 & 10 & 30 \\
GO:2001251 & negative regulation of chromosome organization & 0.00203 & 3 & 12 & 25 \\
GO:2000757 & negative regulation of peptidyl-lysine acetylation & 0.00203 & 4 & 43 & 9 \\
GO:0000725 & recombinational repair & 0.00235 & 4 & 12 & 25 \\
GO:0000724 & double-strand break repair via HR & 0.00235 & 4 & 51 & 8 \\
GO:2001251 & regulation of chromosome organization & 0.00241 & 5 & 125 & 8 \\
GO:0006281 & DNA repair & 0.00295 & 6 & 245 & 2 \\
GO:0006310 & DNA recombination & 0.00327 & 5 & 138 & 4 \\
GO:0000790 & nuclear chromatin & 0.00994 & 5 & 176 & 3 \\
GO:0031056 & regulation of histone modification & 0.0104 & 4 & 84 & 5 \\
GO:0006342 & chromatin silencing & 0.0104 & 3 & 26 & 12 \\
GO:0006342 & DNA replication & 0.0104 & 5 & 184 & 3
\end{tabular}

Figure 2. A functional network analysis of proteins encoded by candidate genes. $(A)$ A network enrichment map showing the relationships between proteins with supported or pathway lesions. Proteins are represented as black dots or nodes, and the relationships between them are represented as colored lines or edges, in which purple lines denote coexpression, pink lines denote physical interactions, orange lines denote predicted interactions, blue lines denote colocalization, and green lines denote shared protein domains. Further clustering (indicated by colored ovals) revealed that most of the proteins group into the broad categories of lipid metabolism and homeostasis (yellow), synaptic function (green), and DNA damage response (blue). Several proteins are also involved in transcriptional repression (purple). Sixty-three percent are included in the broad category regulation of DNA activity (pink). (B) The most enriched Gene Ontology (GO) terms in this network, as determined by their false discovery rate (FDR)-adjusted $q$-value, are double-strand break repair, transcriptional repressor complex, negative regulation of histone acetylation, and regulation of chromatin organization. The percentage coverage indicates the proportion of genes within a given GO ID that are also present in the network.

in the neuron-specific cytochrome P450, family 46, subfamily a, polypeptide 1 (Cyp46a1), which produces 24S-OHC, a molecule essential for cholesterol turnover and a biomarker for abnormal cholesterol homeostasis in the Mecp2 brain (Lund et al. 2003; Buchovecky et al. 2013).

\section{Synapse function}

Mutations that affect synaptic function are expected from previous studies of RTT patients and Mecp2-mutant mice (Chao et al. 2007; Shepherd and Katz 2011; Bellini et al. 2014). A mutation in cadherin, EGF LAG seven-pass G-type receptor 3 (Celsr3) was supported by mating and association analysis, and two additional lines $(604$, A_347N) carried alleles. CELSR3 has a role in glutamatergic synapse formation and neuronal development (Feng et al. 2016; Thakar et al. 2017; Wang et al. 2017). Moreover, Celsr3 is a target of the REST/Co-REST complex, which recruits other proteins including histone deacetylases (HDACs) and the transcriptional regulator SIN3A to mediate long-term gene silencing of target genes in neurons (Ballas et al. 2005; Mandel et al. 2011; Monaghan et al. 2017; Hwang and Zukin 2018). Similarly, drebrin-like $(D b n l)$ is a REST target involved in vesicular trafficking and synapse formation in neurons (Haeckel et al. 2008). Although line 4633 was not mated, it carries a missense mutation in co-REST, Rcor1, which binds and corepresses target genes with MECP2 (Ballas et al. 2005). Other candidate genes that are predicted to function at the synapse are the hyperpolarization-activated, cyclic nucleotide-gated $\mathrm{K}+2$ (Hcn2) and the Rho guanine nucleotide exchange factor (GEF) 15 (Arhgef15).

When MECP2 is absent, NCOR1 does not suppress its lipid synthesis targets, including Sqle, leading to lipid accumulation in the brain and liver of Mecp2-mutant males and females, resulting in metabolic syndrome (Buchovecky et al. 2013; Kyle et al. 2016). Acetoacetyl-CoA synthetase (Aacs) is another target of the NCOR1 corepressor complex (Knutson et al. 2008), which allows ketone bodies to be used as an energy source (Hasegawa et al. 2012a,b). Transmembrane 7 superfamily member 2 ( $T m 7 s f 2$ ) functions just downstream from Sqle in the cholesterol biosynthesis pathway, and its function is linked to liver X receptor (LXR) and NF-kB signaling, suggesting roles in both lipid homeostasis and inflammation (Bellezza et al. 2013). Apolipoprotein A-V (Apoa5) is a key regulator of triglyceride metabolism (Gonzales et al. 2013). ATPase, aminophospholipid transporter (APLT), class I, type 8A, member (Atp8a1) is part of an ATPase-coupled membrane complex involved in vesicle trafficking and the transport of aminophospholipids (Paterson et al. 2006). A mutation in line 920_39R occurred
$\mathrm{Hcn} 2$ is a target of cAMP that regulates neuronal extension (Mobley et al. 2010), and mice that lack Arhgef15 have increased excitatory synapse formation (Margolis et al. 2010). CD22 antigen $(C d 22)$ is a canonical B-cell receptor that clusters in synaptic function because mutations in $C d 22$ increase the ability of microglia to clear myelin debris and remodel dendrites (Pluvinage et al. 2019).

\section{DNA damage response}

Another group of mutations affects the DNA damage response (DDR). Three lines carried mutations in tet methylcytosine dioxygenase 1 (Tet1). TET1 modifies methylated CpG dinucleotides to 5$\mathrm{OH}$ methylated bases in the first step of demethylation by base excision repair (BER) (Weber et al. 2016). Tet1 plays a role in chromosomal stability and telomere length in embryonic stem cells through methylation (Yang et al. 2016). Although only one of

\section{Genome Research}

www.genome.org 
Table 2. Mutations in modifier lines

\begin{tabular}{|c|c|c|c|}
\hline $\begin{array}{l}\text { Gene, } \\
\text { chromosome }\end{array}$ & Supported lesion & Improvement $p \leq 0.5$ & Allele or pathway lesion \\
\hline \multicolumn{4}{|c|}{ DNA damage response } \\
\hline Birc6, Chr 17 & exon49:c.9611G >A:p.R3204Q & Health, weight & exon23:c.4784G > A:p.S1595N (A_83L) \\
\hline NM_007566 & (M_199LL) & Birc6 $\Leftrightarrow D b n /$ longevity & 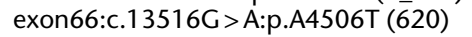 \\
\hline Brca1, Chr 11 & & & exon10:c.679T > A:p.F227I (620) \\
\hline NM_009764 & & & exon4:c.148A > G:p.K50E (A_189N) \\
\hline $\begin{array}{l}\text { Brca2, Chr } 5 \\
\text { NM } 001081001\end{array}$ & & & exon11:c.2107G > T:p.D703Y (A_173N) \\
\hline $\begin{array}{l}\text { Fan1, Chr } 7 \\
\text { NM_177893 }\end{array}$ & exon10:c.2392T > C:p.S798P (A_333N) & Longevity, limb clasping, health & \\
\hline $\begin{array}{l}\text { Mre11a, Chr } 9 \\
\text { NM_018736 }\end{array}$ & & & exon17:c.1915T >A:p.Y639N (M_420L) \\
\hline Rad50, Chr 11 & & & exon16:c.2717A > G:p.K906R (M_79N) \\
\hline NM_009012 & & & \\
\hline $\begin{array}{l}\text { Rbbp8, Chr } 18 \\
\text { NM } 001081223\end{array}$ & exon15:c.2227C > T:p.Q743X (895) & $\begin{array}{l}\text { Longevity } \\
\text { Rbbp8@Sale longevity }\end{array}$ & \\
\hline $\begin{array}{l}\text { Spin1, Chr } 13 \\
\text { NM_146043 }\end{array}$ & exon4:c.696C>A:p.Y232X (4751) & Longevity, limb clasping & \\
\hline $\begin{array}{l}\text { Tet1, C̄hr } 10 \\
\text { NM_027384 }\end{array}$ & exon1:c.241A > T:p.M81L (A_27R) & Longevity, muscle tone, activity & $\begin{array}{l}\text { exon2:c.1909G > T:p.V637F (136) } \\
\text { exon1:c.1636T > C:p.S546P (591) }\end{array}$ \\
\hline \multicolumn{4}{|l|}{ Lipid metabolism } \\
\hline $\begin{array}{l}\text { Aacs, Chr } 5 \\
\text { NM_030210 }\end{array}$ & exon8:c.770T > C:p.V257A (4799) & $\begin{array}{l}\text { Longevity, health, limb clasping } \\
\text { Atp8a1 } \Leftrightarrow \text { Aacs longevity, health }\end{array}$ & \\
\hline $\begin{array}{l}\text { Apoa5, Chr } 9 \\
\text { NM_080434 }\end{array}$ & exon4:c.1061A > T:p.D354V (J_57L) & $\begin{array}{l}\text { Limb clasping, muscle tone, activity } \\
H c n 2 \Leftrightarrow A p o a 5 \text { muscle tone }\end{array}$ & \\
\hline $\begin{array}{l}\text { Atp8a1, Chr } 5 \\
\text { NM_009727 }\end{array}$ & exon22:c.2037T >A:p.N679K (4799) & $\begin{array}{l}\text { Health, limb clasping, muscle tone, } \\
\text { activity } \\
\text { Atp8a1 } \Leftrightarrow \text { Aacs longevity, health }\end{array}$ & \\
\hline $\begin{array}{c}\text { Cyp46a1, Chr } 12 \\
\text { NM_010010 }\end{array}$ & & & exon3:c.263C > T:p.T88M (920_39R) \\
\hline $\begin{array}{l}\text { Sqle, Chr } 15 \\
\text { NM_003129 }\end{array}$ & exon6:c.1195C>T:p.R399X (895) & $\begin{array}{l}\text { LOD } 3.03 \text { longevity } \\
\text { Rbbp8 } \Leftrightarrow \text { Sqle longevity }\end{array}$ & \\
\hline $\begin{array}{r}\text { Tm7sf2, Chr } 19 \\
\text { NM_028454 }\end{array}$ & exon6:c.697T > C:p.Y233H (4654) & $\begin{array}{l}\text { Limb clasping, muscle tone, activity } \\
\text { Dennd } 4 a \Leftrightarrow T m 7 s f 2 \text { longevity }\end{array}$ & \\
\hline \multicolumn{4}{|l|}{ Synapse function } \\
\hline $\begin{array}{l}\text { Arhgef15, Chr } 11 \\
\text { NM_177566 }\end{array}$ & exon2:c.275A > G:p.D92G (4751) & Limb clasping, muscle tone, activity & exon2:c.181A>T:p.161F (A_230RR) \\
\hline $\begin{array}{l}\text { Cd22, Chr } 7 \\
\text { NM_009845 }\end{array}$ & exon13:c.2414A > G:p.Q805R (520) & $\begin{array}{l}\text { Health, limb clasping } \\
C d 22 \Leftrightarrow \text { Clint } 1 \text { longevity, muscle tone, } \\
\text { activity }\end{array}$ & \\
\hline $\begin{array}{l}\text { Celsr3, Chr } 9 \\
\text { NM_080437 }\end{array}$ & $\begin{array}{l}\text { exon22:c.7415T > A:p.V2472E } \\
\quad\left(918 \_15 L\right)\end{array}$ & Longevity, health, limb clasping & $\begin{array}{l}\text { exon17:c.6459C > A:p.C2153X (604) } \\
\text { exon4:c.4604T > A:p.V1535E (A_347N) }\end{array}$ \\
\hline $\begin{array}{l}\text { Dbnl, Chr } 11 \\
\text { NM_001146308 }\end{array}$ & exon8:c.709T > A:p.S237T (M_199LL) & $\begin{array}{l}\text { ns } \\
\text { Birc } 6 \Leftrightarrow D b n / \text { longevity }\end{array}$ & \\
\hline $\begin{array}{l}\text { Hen2, Chr } 10 \\
\text { NM_008226 }\end{array}$ & exon1:c.502C > T:p.R168C (J_57L) & $\begin{array}{l}\text { Longevity, muscle tone, activity, weight } \\
\operatorname{Hcn} 2 \Leftrightarrow A \text { poa } 5 \text { muscle tone }\end{array}$ & \\
\hline $\begin{array}{l}\text { Kdm4a, Chr } 4 \\
\text { NM_001161823 }\end{array}$ & exon4:c.396T > A:p.Y132X (520) & Longevity, health, limb clasping & \\
\hline \multicolumn{4}{|c|}{ Regulation of DNA activity } \\
\hline $\begin{array}{l}\text { Gtf3c5, Chr } 2 \\
\text { NM_148928 }\end{array}$ & exon9:c.1169A > G:p.D390G (4654) & Longevity, muscle tone, activity & \\
\hline $\begin{array}{l}\text { Prdm15, Chr } 16 \\
\text { NM_114604 }\end{array}$ & splicing, c.2099257392 A>C (352) & LOD 4.82 longevity & \\
\hline $\begin{array}{l}\text { Zbtb4 1, Chr } 1 \\
\text { NM_172643 }\end{array}$ & exon3:c.1236C > A:p.N412K (M_333R) & Longevity & exon11:c.2344C>A:p.Q782K (J_136N) \\
\hline $\begin{array}{l}\text { Zzz3, C̄hr } 3 \\
\text { NM_108946 }\end{array}$ & exon4:c.1682C > T:p.T1303I (856ª) & LOD 3.61 longevity & \\
\hline \multicolumn{4}{|c|}{ Transcriptional repression } \\
\hline $\begin{array}{l}\text { Ncor1, Chr } 11 \\
\text { NM_177229 }\end{array}$ & & & exon9:c.866T > C:p.M289T (620) \\
\hline $\begin{array}{l}\text { Ncor1, Chr } 11 \\
\text { NM_001252313 }\end{array}$ & & & exon17:c.2043A>T:p.Q681H (S_165N) \\
\hline $\begin{array}{l}\text { Rcor1, Chr } 12 \\
\text { NM_198023 }\end{array}$ & & & exon8:c.650A > T:p.Q217L (4633) \\
\hline $\begin{array}{l}\operatorname{Sin} 3 a, \text { Chr } 9 \\
\text { NM_001110350 }\end{array}$ & & & exon13:c.1907C > T:p.A636V (272) \\
\hline $\begin{array}{l}\text { Tb/1 xrī, Chr } 3 \\
\text { NM_030732 }\end{array}$ & & & exon12:c.1081G > T:p.G361C (J_157N) \\
\hline
\end{tabular}


Table 2. Continued

\begin{tabular}{|c|c|c|c|}
\hline $\begin{array}{l}\text { Gene, } \\
\text { chromosome }\end{array}$ & Supported lesion & Improvement $\mathrm{p} \leq 0.5$ & Allele or pathway lesion \\
\hline \multicolumn{4}{|l|}{ Unknown } \\
\hline $\begin{array}{l}\text { Clint1, Chr } 11 \\
\text { NM_001045520 }\end{array}$ & exon12:c.1730T > C:p.M577T (520) & $\begin{array}{l}\text { ns } \\
\text { Cd22 } \Leftrightarrow \text { Clint1 longevity, muscle tone, }\end{array}$ & \\
\hline $\begin{array}{l}\text { Dennd4a, Chr } 9 \\
\text { NM_001162917 }\end{array}$ & exon15:c.1778C > T:p.A593V (4654) & Dennd $4 a \Leftrightarrow T m 7 s f 2$ longevity & \\
\hline
\end{tabular}

Association scores are in Supplemental Table S3, and LOD scores were previously published.

Candidate genes fall into three primary functional pathways: DNA damage response, lipid metabolism, synapse function. Other candidate genes fall into the categories of regulation of DNA activity or transcriptional repression. Column 2 shows the mouse line that carries the mutation in brackets. Animals were improved for longevity, additive subjective health score, limb clasping, activity, or muscle tone scores individually combined over 3 wk or body weight at $8 \mathrm{wk}$. The tremor score did not change significantly for any line, so is not included individually. The grooming score did not accurately reflect health, so is not included individually.

(ns) Not significant; $(\Leftrightarrow)$ indicates that pairwise interaction of candidate genes influenced the phenotype.

a Line 856 also revealed linkage with Mmu Chr 6, LOD 3.9.

the Tet1 lesions is supported by mating and association analysis in line A_27R, all three are missense mutations that lie in evolutionarily conserved amino acids near the $\mathrm{CpG}$ binding domain (Supplemental Fig. S1A). Mutations in the E2/E3 ubiquitin ligase baculoviral IAP repeat-containing 6 (Birc6, also called BRUCE) were also found in three lines (Supplemental Fig. S1B), and one in line M_199L was confirmed by mating and association analysis. BIRC6 stabilizes TRP53 in a first step toward inhibiting apoptosis (Ren et al. 2005), but BIRC6 also regulates the BRIT1SWI-SNF double-strand break (DSB) response (Ge et al. 2015). BIRC6-depleted cells display reduced homologous recombination repair, and Birc6-mutant mice show repair defects and genomic instability (Lotz et al. 2004; Ren et al. 2005). The mutation in Spindlin 1 (Spin1) lies within its third TUDOR-like domain (Supplemental Fig. S2), which binds methylated histone H3, a mark associated with DDR (Chew et al. 2013; Choi et al. 2017; Shanle et al. 2017).

Additional mutations lie in components of the DSB repair pathway. A mutation in retinoblastoma binding protein 8 , endonuclease $(R b b p 8)$ occurred in exon 15 , which results in a premature stop codon that predicts a truncated protein in the critical C-terminal domain (Fig. 3A). RBBP8 acts with BRCA1 to regulate the DSB repair choice between homologous recombination directed repair (HDR) or nonhomologous end joining (NHEJ) (Huertas 2010; Escribano-Díaz et al. 2013), supporting the initial steps of DNA resection and recruiting other DNA repair proteins in dividing cells (Makharashvili et al. 2014). When RBBP8 is absent, NHEJ is the preferred choice for DDR repair. A survival curve shows that Mecp2/Y mice carrying the Rbbp8 suppressor mutation show significantly improved longevity (Median survival of $112 \mathrm{~d}$ for $M e c p 2 / \mathrm{Y} ; R b b p 8^{+/-}$vs. $77 \mathrm{~d}$ for $M e c p 2 / \mathrm{Y} ; R b b p 8^{+/+}$) (Fig. 3B). Moreover, $R b b p 8$ expression is increased in Mecp $2 / \mathrm{Y}$ mouse brain at a symptomatic time point of $8 \mathrm{wk}$ (Fig. 3C). Together, these data suggest that elevated RBBP8 in Mecp2-null mice may cause pathology that is ameliorated by reducing the amount of the protein.

Previous reports show that mesenchymal and neural stem cells derived from Mecp2/Y mice have elevated DSBs (Squillaro et al. 2010; Alessio et al. 2018). DSBs are initially detected by the MRE11-RAD50-NBN (MRN) sensor complex, which activates the ATM or ATR kinases, leading to the phosphorylation of several downstream targets (Falck et al. 2012). RBBP8 also plays a role in the removal of topoisomerase II (TOP2)-induced DNA DSBs, where it partners with BRCA1 to initiate DNA resection before repair (Fig. 3D; Aparicio et al. 2016). Many other factors are involved in the resolution of the DSB, including BRCA2 and FANCD2/FANCI-associated nuclease 1 (FAN1) (Orthwein et al. 2015). Two mutations in Brca1 and one in each of Mre11a, Rad50, Fan1, and Brca2 were also observed (Table 2; Supplemental Fig. S2). To examine the extent of involvement of the DDR pathway, the expression of several components of the HDR (Mre11a, Rad50, Atr, Nbn, Cdk1, Rpa2) and NHEJ (Xrcc5, Trp53bp1, Prkdc) pathways were also assessed in the brains of 8-wk-old Mecp2/Y and $+/ \mathrm{Y}$ mice. Expression of $\mathrm{Nbn}$, as well as Atr, which transduces signals from the MRN complex, increased in whole Mecp2/Y mouse brain. Conversely, the expression of Trp53bp1 decreased (Fig. 3D). TRP53BP1 functions in a manner antagonistic to RBBP8, blocking resection to promote NHEJ (Escribano-Díaz et al. 2013).

\section{Combinatorial mutations that improve health fall into different pathways}

Association analysis of pairwise gene-gene interactions reveals six lines in which the presence of more than one mutation confers increased improvement in individual health traits (Fig. 4A; Supplemental Tables S2, S3). In line 520, the improvement segregated independently, suggesting two suppressors, so four N3 animals instead of two were sequenced. Consistently, mutations in both $C d 22$ and $K d m 4 a$ independently improved traits, but did not further improve traits when inherited together. However, the combined Cd22 and Clint1 mutations improved activity and muscle tone, although Clint1 did not improve traits when inherited alone. Similarly, a mutation in Gtf3c5 in line 4654 improved longevity, activity, and muscle tone independently of $T m 7 s f 2$. The mutation in Tm7sf2 improved limb clasping, activity, and muscle tone, yet longevity was not improved unless the animals also carried a mutation in Dennda. Dbnl did not improve phenotypes alone in line M_199L, yet improved longevity when a mutation in Birc6 was present. The combination of mutations in Hcn2 and Apoa5 in line J_57L is associated with improved muscle tone. In most cases, the associated genes belonged to different pathways (Fig. 4A). The exception is line 4799 where the combination of Aacs and Atp8a1 improves

\section{Genome Research}

www.genome.org 
A

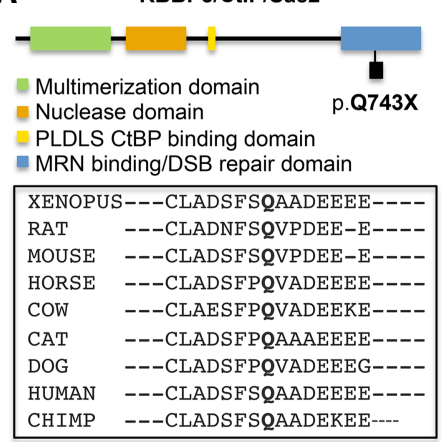

B

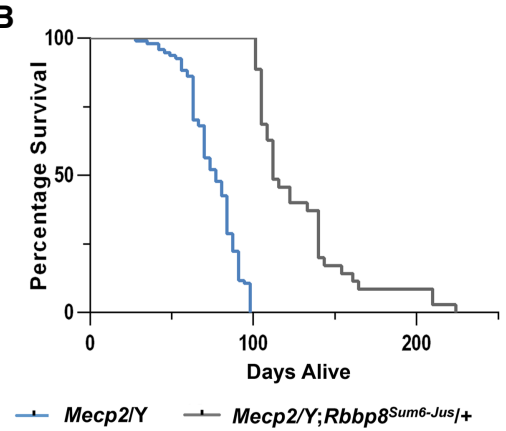

C

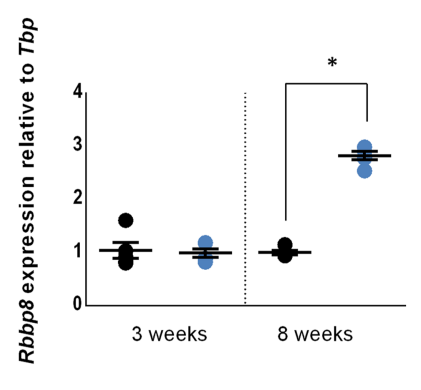

D

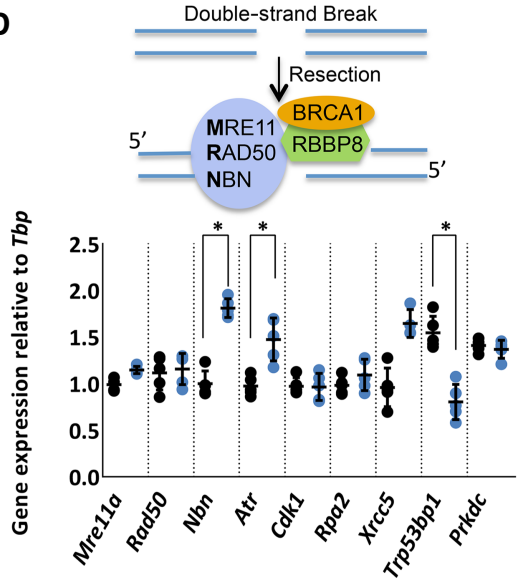

Figure 3. The DNA damage response (DDR) pathway is implicated in a Mecp2/Y mouse model of Rett syndrome. (A) An ENU-induced nonsense mutation occurs at position p.Q743X within the critical C-terminal double-strand break (DSB) repair domain (blue) of RBBP8, also called CtBP interacting protein CtIP or SAE2 in yeast. Amino acid alignments generated using Clustal Omega show that this glutamine residue is well conserved among organisms from Xenopus to human. (B) Mecp2/Y;Rbbp8 $8^{\text {Sumb-Jus/+ }}$ mice (gray) have increased longevity $(n=35$, Median survival $112 \mathrm{~d})$ when compared to Mecp2/Y mice (blue) $(n=$ 94 , Median survival $77 \mathrm{~d}$ ) without secondary mutations $(P<0.0001$ by Mantel-Cox test). (C) Rbbp 8 transcripts are elevated in symptomatic at 8 wk Mecp2/Y (blue) brain compared to $+/ Y$ (black), but unchanged at 3 wk. Results are representative of three independent experiments $(P<0.01$ by the twosample Student's t-test, $+/ Y: n=5$, Mecp2/Y: $n=5$ ); error bars represent SEM. $(D)$ Double-strand break repair by homologous recombination involves the recruitment of RBBP8 to the site of the break in an MRN/BRCA1-dependent manner. RBBP8 partners with BRCA1 to initiate DNA resection. Transcript levels of genes involved in $\mathrm{HR}$, nibrin ( $\mathrm{Nbn}$ ) and ataxia telangiectasia and Rad3 related (Atr) are elevated at $8 \mathrm{wk}$ in Mecp2/Y (blue) brain, whereas NHEJ gene transformation related protein 53 binding protein 1 (Trp53bp1) is decreased compared to $+/ Y$ (black) $(P<0.05$ by the two-sample Student's $t$-test, $+/ Y: n=5$, Mecp2/Y: $n=5)$; error bars represent SEM.

longevity and health, but both genes are predicted to function in different aspects of lipid homeostasis-namely, energy utilization and lipid trafficking.

The founder of line 895 showed extreme longevity and was sacrificed at the age of $14 \mathrm{mo}$. The pattern of inheritance of line 895 indicated that he carried two different suppressor mutations (Table 1). One, a nonsense mutation in Sqle, was first identified by linkage (Chromosome 15, LOD 3.03). N3 males from line 895 that had a longer life were bred to segregate and identify the second locus by backcrossing again to $129 \mathrm{~S} 6 / \mathrm{SvEv}$ animals to generate N4 and N5 generations (Supplemental Table S2). Genotyping and segregation analysis revealed that a nonsense mutation in Rbbp8 (Chromosome 18) was consistent with trait improvement. Subsequent genotyping of animals from line 895 for Sqle and $R b b p 8$ showed that although either mutation alone was associated with improved longevity, the presence of both mutations conferred extreme longevity (Fig. 4B). Seven animals from the N3 and N5 generations inherited both loci, and all lived longer than $29 \mathrm{wk}$, with a range of $29-116 \mathrm{wk}$ (203-812 d). These data suggest that combining mutations from different pathways may further improve health in Mecp2/Y mice.

\section{Discussion}

Genetic modifier screens are mainly carried out in fruit flies, worms, yeast, and bacteria to discover genes that are members of a developmental or biochemical pathway. The suppressor screen reported here represents the largest screen yet carried out in the mouse, and, by using massively parallel sequencing and association analysis, the screen identifies the largest number of candidate genes. Applications of modifier screens in the mouse are powerful (Carpinelli et al. 2004; Matera et al. 2008; Westrick et al. 2017). Even so, the mutations are identified based on their ability to suppress or enhance a mutant phenotype. Consequently, at least two mutations must be segregated to follow the phenotype, requiring an extensive amount of breeding. In the screen reported here, most lines showed evidence for complex trait inheritance, predicting that more than one modifier segregated. In a recent published modifier screen for thrombosis, very few candidate genes were identified, likely because of the lack of power in finding linkages using standard quantitative trait mapping strategies (Tomberg et al. 2018). Here, statistical tests that assessed association instead of linkage were used to identify multiple interacting loci in six lines, three of which had an effect only in the presence of other modifiers. These data show the power of ENU for inducing and identifying complex genetic interactions. However, the screen has limitations, of which the most relevant to RTT is the restriction of assessments to male mice, rather than females, whose variable penetrance and late onset of phenotypes preclude efficacy in a high-throughput screen.

ENU is expected to induce mutations randomly, but large genes are likely to have more mutations than small ones. Ttn is mutated in nearly every ENU screen because of its size (the cDNA is 81,843 base pairs, encompassing 192 exons), and 20 alleles were isolated here. Therefore, we cannot be certain that some genes had mutations because of their size, rather than their ability to modify Mecp2. Tet1 had three alleles, and is a relatively small gene, which has 13 exons. Birc6 also had three alleles, yet has 73 exons. Therefore, although alleles are called, some of the lesions may not suppress phenotypes. This scenario shows that mating all lines for inheritance and segregation is ideal. However, all of the founder lines reported here were not mated owing to time, cost, and animal space limitations. Our hope was that by identifying pathways, the number of animals used in breeding could be reduced. Candidate genes in any line can be confirmed after reanimation by IVF or by using CRISPR/Cas9 genome editing. 
A

\begin{tabular}{|c|c|c|c|c|c|}
\hline Line & $\begin{array}{l}\text { Synapse } \\
\text { function }\end{array}$ & $\begin{array}{l}\text { Lipid } \\
\text { homeostasis }\end{array}$ & DNA integrity & Other & $\begin{array}{l}\text { Combination } \\
\text { Improvement }\end{array}$ \\
\hline 895 & & $S q l e^{\text {Sum3-Jus }}$ & $R b b p 8^{\text {Sum6-Jus }}$ & & Yes \\
\hline 520 & $\begin{array}{l}C d 22^{\text {Sum7-Jus }} \\
C d 22^{\text {Sum7-Jus }} \\
\end{array}$ & & $K d m 4 a^{\text {Sum8-Jus }}$ & Clint1 ${ }^{\text {Sum7i-Jus }}$ & $\begin{array}{l}\text { No } \\
\text { Yes }\end{array}$ \\
\hline 4654 & & $\begin{array}{l}T m 7 s f 2^{\text {Sum9-Jus }} \\
T m 7 s f 2^{\text {Sumg-Jus }}\end{array}$ & & $\begin{array}{l}\text { Gtf3c5 } 5^{\text {Sum 10-Jus }} \\
\text { Dennd4a }\end{array}$ & $\begin{array}{l}\text { No } \\
\text { Yes }\end{array}$ \\
\hline 4751 & Arhgef15 ${ }^{\text {Sum11-Jus }}$ & & Spin1 $1^{\text {Sum12-Jus }}$ & & No \\
\hline 4799 & & $\begin{array}{l}\text { Aacs } \\
\text { Atp }^{\text {Sum13-Jus }} 1^{\text {Sum14-Jus }}\end{array}$ & & & Yes \\
\hline J_57L & $\mathrm{Hcn} 2^{\text {Sum16-Jus }}$ & $A p o a 5^{\text {Sum17-Jus }}$ & & & Yes \\
\hline M_199L & $\left.D b n\right|^{\text {Sum20i-Jus }}$ & & Birc6 $6^{\text {Sum 20-Jus }}$ & & Yes \\
\hline
\end{tabular}

B

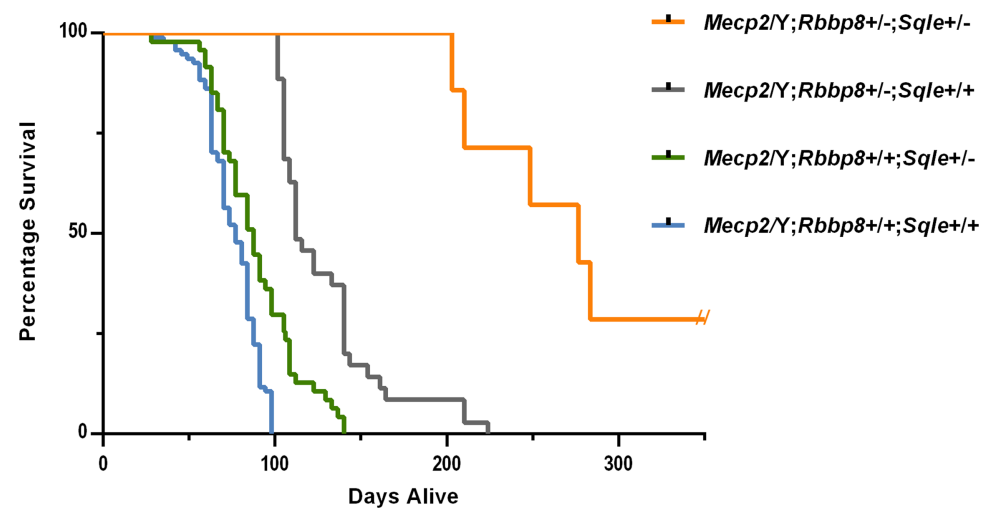

Figure 4. Combinatorial effects of multiple mutations on health and longevity. (A) Multiple lines (895, 520,4654, 4751, 4799, J_57L, and M_199L) carry lesions in more than one gene that either independently or additively improve health. $\bar{K} d m 4 a$ and $C d 22$ in line $520, T m 7 s f 2$ and Gtf3c5 in line 4654, and Arhgef15 and Spin1 in line 4751 show independent effects on health, whereas the other mutations show positive combinatorial effects on Mecp2/Y health. (B) Mecp2/Y mice from line 895 , carrying mutations in Sqle and/or Rbbp8, show increased longevity when both mutations are present (Mecp2/Y; $\mathrm{Rbbp8}^{+/-} ; \mathrm{Sqle}^{+/-} ; n=7$, median survival $277 \mathrm{~d}$ ) when compared to Mecp2/Y mice carrying either muta-

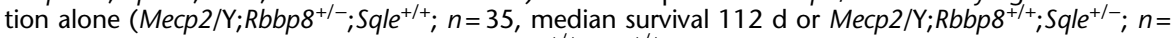

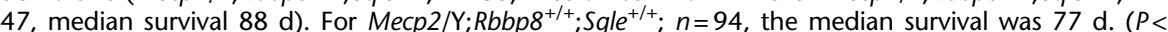
0.0001 by Mantel-Cox test, for each comparison of Mecp2/Y;Rbbp $8^{+/+} ; S_{q l} e^{+/+}$to any of the three groups). These data include the founder 895, N3 animals (genotyped for both Rbbp8 and Sqle) and all of the N5 animals generated.

All of the potential modifiers were not identified. First, the screening relied on subjective health parameters and did not include a quantitative test for neurological function. Thus, modifier traits could be overlooked and/or misjudged. Although this may imply a need for more prescriptive assessments of RTT-like phenotypes, time and cost preclude such evaluations in a high-throughput screen. DNA variants could also be missed; as evidence, line 856 had a strong LOD score for a second modifying locus on Chromosome 6, yet WES did not identify a candidate in the region. Many factors can influence the observation that WES falls short of identifying all lesions, in part because DNA quality can influence depth of coverage, making heterozygous mutations difficult to call. Moreover, genome annotation in the mouse remains incomplete, with missing segments and incompletely annotated exons. For example, the suppressor in line 1395 mapped to an unannotated region of mouse Chromosome 7. Finally, loci present in the two inbred strains used here may also influence the penetrance of traits, yet modifying loci in the strain backgrounds were not a priority for identification.

The inheritance of haplotypes can also make linked ENU-induced mutations difficult to sort as causative (Neuhaus and Beier 1998). In line A_333N, two mutations had very strong association scores as potential modifiers: A mutation in SH3 and multiple ankyrin repeat domains 1 (Shank1) was a strong candidate gene based on its autism associations, whereas a mutation in Fan1 would be consistent with the DDR pathway. However, these two genes lie only $20 \mathrm{Mb}$ apart on Chromosome 7. Nine animals showed crossovers between the two loci, suggesting that the mutation in Fan1 was the more strongly supported modifier, and there was no association with their inheritance together. In contrast, although Aacs and Atp8a1 lie $60 \mathrm{Mb}$ from each other on Chromosome 5, the mutations in each showed strong association with trait improvement, and their inheritance together further improved the traits. These data show that in these small family data sets without additional fine structure mapping crosses, candidate genes could be resolved by recombination and association analysis. However, the associative candidate genes are not confirmed by fine mapping, complementation, or functional studies, so should be confirmed by additional experiments.

An unbiased modifier approach has implicated several pathways in RTT pathogenesis, one of which supports the idea of improving synaptic signaling for treatment, as expected from published evidence. Even so, our study suggests additional avenues for intervention. For example, CD22 responds to 2-hydroxypropyl-beta-cyclodextrin, which is in phase 2 and 3 clinical trials for Niemann-Pick disease, to reduce microglia-associated defects (Cougnoux et al. 2018), and antibodies directed against CD22 reduce microglial impairment in aging brains (Pluvinage et al. 2019). In addition, other pathways suggest that alternative avenues for intervention should be considered when studying RTT pathogenesis. Lipid homeostasis is directly regulated by an interaction between MECP2 and the NCOR1 corepressor complex (Kyle et al. 2016). Mutations in MECP2's NCOR interaction domain (NID) cause classical RTT in humans (Heckman et al. 2014) and RTT-like phenotypes in mice (Lyst et al. 2013), highlighting the importance of the NCOR1 interaction with MECP2 in RTT pathology. The NCOR complex is a master regulator of metabolism, playing roles in lipid biogenesis, glucose utilization, and mitochondrial energy efficiency (Mottis et al. 2013). It follows that metabolism, which is a highly druggable target, should be carefully examined in Mecp2 mice and in RTT patients.

This work suggests a role for DDR in RTT pathology for the first time. The genomic DNA of all cells must be protected from detrimental changes (Madabhushi et al. 2014), and MECP2's absence is associated with the accumulation of genetic damage (Muotri et al. 2010; Squillaro et al. 2010; Alessio et al. 2018). DSBs occur in all neural precursor cells and are important for normal neuronal development. However, the role of DNA integrity in mature neurons is less thoroughly understood. In neurons, topoisomerase II-mediated DSBs occur to relieve topological stress

\section{Genome Research}

www.genome.org 
during transcription (Suberbielle et al. 2013; Madabhushi et al. 2015). This in turn impacts gene expression, especially of neuronal early response genes important for synapse development and maturation, neurite outgrowth, the balance between excitatory and inhibitory synapses, and learning and memory. Robust mechanisms must be in place to rapidly and efficiently repair these DSBs; when these mechanisms fail, the accumulation of DSBs in the brain is a contributor to number of neurological diseases (Frappart and McKinnon 2008; Merlo et al. 2016). It is likely that elevated RBBP8 in Mecp2-null cells is a result of increased DSBs, making increased HDR and/or decreased NHEJ in Mecp2-null neurons important for understanding RTT pathology.

Altogether, the Mecp2 suppressor mutations paint a picture of altered metabolism and DNA damage that modulate synaptic function to cause pathology in Rett syndrome. FAN1 is also a modifier of Huntington's disease phenotypes in humans (Genetic Modifiers of Huntington's Disease (GeM-HD) Consortium 2019); thus, the modifiers found here could be common to other neurological diseases. Many of the lines with the largest degree of symptom improvement carry at least two modifiers, which may reflect a lack of quantitative phenotyping. Even so, combining modifiers often improves symptoms, suggesting that combination therapies for RTT will be more effective than any single therapy. The results underscore the power of a genetic screen for understanding RTT biology because they demonstrate how a modifier screen in mammals is possible, especially for disease genes that are not present in more tractable genetic organisms. With new sequencing technologies and statistical approaches, such a screen should be amenable for nearly any gene for which phenotypes can be clearly assessed. Modifier screens in model organisms may thus help to identify the multitude of genetic variants that influence human disease presentation, as they may point to therapeutic entry points (Enikanolaiye and Justice 2019).

\section{Methods}

\section{Animals}

All animal experiments were conducted under protocols approved by local Animal Care and Use Committees at Baylor College of Medicine (BCM) or at The Centre for Phenogenomics (TCP) accredited by the American Association for Laboratory Animal Care (AALAC) and Canadian Council on Animal Care (CCAC), respectively. Congenic 129.Mecp $2^{\text {tm1.1Bird/+ }}$ female mice were maintained by backcrossing females to males of the $129 \mathrm{~S} 6 / \mathrm{SvEvTac}$ strain. 129.Mecp2 $2^{\text {tm1.1Bird }} / \mathrm{Y}$ (Mecp2/Y, which are Mecp2-null) and age matched wild type $(+/ Y)$ littermate controls were housed in plastic Tecniplast cages with corncob bedding in rooms alternating 12-h and 12-h periods of light and dark, were provided acidified water and a Harlan Teklad 2920X diet ad libitum (19.1\% protein, $6.5 \%$ fat; 0\% cholesterol) (BCM) or Harlan Teklad 2919 (19\% protein, 9\% fat) (The Center for Phenogenomics-TCP). The BCM colony allowed helicobacter, whereas mice were embryo rederived into TCP, which allows no common pathogens. C57BL/6J males were obtained from The Jackson Laboratory (Bar Harbor, ME) at six weeks of age, and injected with three weekly doses of 100 $\mathrm{mg} / \mathrm{kg}$ ENU at $8 \mathrm{wk}$ as described (Kile et al. 2003). After recovery of fertility, ENU-treated males were mated to 129.Mecp $2^{\text {tm1.1Bird/+ }}$ females, and their N1 male offspring were genotyped for the Mecp2 mutation according to The Jackson Laboratory standard protocol using an Applied Biosystems thermocycler and resolution on a QiAxcel (Qiagen).
For 30 of the founder lines, N1 males showing signs of improvement were mated to $129 \mathrm{~S} 6 / \mathrm{SvEvTac}$ females, or sperm was frozen and IVF was performed with oocytes from 129S6/SvEvTac females by the Cryopreservation and Recovery Core, TCP.

\section{Sequencing pipeline}

DNA was extracted from mouse tails using standard methods (Supplemental Methods). For sequencing by The Centre for Applied Genomics (TCAG), 500 ng of genomic DNA was fragmented to $200 \mathrm{bp}$ on average using a Covaris LE220 instrument. Sheared DNA was end-repaired and the $3^{\prime}$ ends adenylated before ligation of adapters with overhang-T. PCR amplified genomic libraries were exome captured, pooled, and sequenced with the TruSeq SBS sequencing chemistry using a V4 high-throughput flowcell on a HiSeq 2500 platform following Illumina's recommended protocol. Approximately 6-8 gb of raw paired end data of 126 bases were generated per exome library. Inbred strain polymorphisms as well as systematic sequencing artifacts, were removed from consideration if identified in the parental strains, dbSNP, or other founder males sequenced in this study, and detrimental variants were called using standard tools and custom scripts (Supplemental Code) (Li et al. 2009; Li and Durbin 2010). Candidate lesions were confirmed by Sanger sequencing before genotyping N3 animals (Supplemental Fig. S3). Primer sequences for each locus are in Supplemental Table S4.

\section{Quantitative reverse transcription polymerase chain reaction (qRT-PCR)}

Whole brain tissue was homogenized and total RNA isolated (Qiagen RNeasy Lipid Tissue Mini Kit) for qRT-PCR analysis (Kyle et al. 2016). Expression was normalized to TATA-binding protein $(T b p)$ as an internal control and results analyzed using the $2^{-(\Delta \Delta \mathrm{CT})}$ method. Primer sequences are in Supplemental Table S5.

\section{Statistics}

Complex versus Mendelian inheritance was assessed from the number of animals that inherited trait improvement or longevity in each N2 family (Supplemental Table S2). For each line, the decomposition of N3 improved cases across N2 families is tested for the Mendelian hypothesis by generating data conditional on whether or not $\mathrm{N} 2$ animals inherited the trait given the presence (with probability 0.50 ) or absence (with probability 0.25 ) of an $\mathrm{N} 3$ offspring with improvement in the family. The $P$-value is calculated considering the number of as-or-more extreme cases under the same family configuration than the one observed.

In screen 2, associations of genetic loci with outcomes based on subjective health parameters were assessed using cumulative link models (CLM) suitable for ordinal data (Agresti 2011; https ://cran.r-project.org). The health score, limb clasping, tone, activity, and tremor scores were fitted to separate models. Association with body weight at $8 \mathrm{wk}$ was inferred using linear models. In either model, random effects were included to account for potential clustering of outcomes within families. However, in almost all cases, random effects had a negligible variance suggesting that there was no significant clustering of the outcomes, allowing for the fitted models to include only fixed effects. The associations of genetic loci with the longevity (time to sacrifice) were assessed using parametric survival models, in which the final model for each line was selected using the Akaike Information Criterion (AIC) (Akaike 1974). For each line, marginal effects of each gene were investigated, as well as pairwise gene-gene interactions on each trait and the survival models. All association analyses were performed using the R statistical programing software (R Core Team 2019), 
along with the packages ordinal (https://cran.r-project.org), lme4 (Bates et al. 2015), and flexsurv (Jackson 2016).

Kaplan-Meier survival curves in Figures $2 \mathrm{~B}$ and $4 \mathrm{~B}$ were generated in GraphPad Prism 8 followed by the Mantel-Cox test (logrank comparison). Comparisons between two groups, as in qPCR experiments, were carried out in GraphPad Prism 8 using the two-sample Student's $t$-test.

\section{Data access}

The N1 founder whole-exome sequencing data generated in this study have been submitted to the NCBI BioProject database (https://www.ncbi.nlm.nih.gov/bioproject/) under accession number PRJNA603006.

\section{Competing interest statement}

The authors declare no competing interests.

\section{Acknowledgments}

The Centre for Applied Genomics (TCAG) generated sequence for founder animals from screen 2 and was crucial in analyzing the sequence. We thank Jeff McDonald of TCAG for helping to deposit the sequence files in National Center for Biotechnology Information (NCBI). The Canadian Mutant Mouse Repository Cryopreservation and Recovery Core at the Centre for Phenogenomics (TCP) carried out the sperm freezing and in vitro fertilization (IVF), which could not have been done without the expertise of Dr. Lauryl Nutter and Marina Gertenstein. We thank Dr. Dan Durocher for advice in examining the DNA damage response pathway; Ashlee Dargie, Travis Brooke-Bisschop, and Stephen McDonald for technical assistance; and Dr. Rebekah Tillotson and Neeti Vashi for critical review. This work was supported by grants from the Rett Syndrome Research Trust and the Canadian Institute for Health Research Foundation Scheme FDN-154273 to M.J.J.

Author contributions: M.J.J. conceived of the work, obtained funding, assessed phenotypes, and wrote the manuscript. A.E. generated data for the DSB pathway, performed functional network analysis, and wrote the manuscript. J.R. oversaw the screen husbandry, assessed phenotypes, organized data, and wrote the manuscript. C.M.B., C.T., and M.S. generated data. R.Z. and J.S. generated and analyzed sequencing data. E.A. performed statistical analysis and wrote the manuscript.

\section{References}

Agresti A. 2011. Categorical data analysis. Wiley, Hoboken, NJ.

Akaike H. 1974. A new look at the statistical model identification. IEEE Trans Autom Control 19: 716-723. doi:10.1109/TAC.1974.1100705

Alessio N, Riccitiello F, Squillaro T, Capasso S, Del Gaudio S, Di Bernardo G, Cipollaro M, Melone MAB, Peluso G, Galderisi U. 2018. Neural stem cells from a mouse model of Rett syndrome are prone to senescence, show reduced capacity to cope with genotoxic stress, and are impaired in the differentiation process. Exp Mol Med 50: 1. doi:10.1038/s12276017-0005-X

Aparicio T, Baer R, Gottesman M, Gautier J. 2016. MRN, CtIP, and BRCA1 mediate repair of topoisomerase II-DNA adducts. J Cell Biol 212: 399408. doi:10.1083/jcb.201504005

Ballas N, Grunseich C, Lu DD, Speh JC, Mandel G. 2005. REST and its corepressors mediate plasticity of neuronal gene chromatin throughout neurogenesis. Cell 121: 645-657. doi:10.1016/j.cell.2005.03.013

Bates D, Mäechler M, Bolker B, Walker S. 2015. Fitting linear mixed-effects models using lme4. J Stat Softw 67: 1-48. doi:10.18637/jss.v067.i01

Bellezza I, Roberti R, Gatticchi L, Del Sordo R, Rambotti MG, Marchetti MC Sidoni A, Minelli A. 2013. A novel role for Tm7sf2 gene in regulating
TNF $\alpha$ expression. PLoS One 8: e68017. doi:10.1371/journal.pone .0068017

Bellini E, Pavesi G, Barbiero I, Bergo A, Chandola C, Nawaz MS, Rusconi L, Stefanelli G, Strollo M, Valente MM, et al. 2014. MeCP2 post-translational modifications: a mechanism to control its involvement in synaptic plasticity and homeostasis? Front Cell Neurosci 8: 236. doi:10.3389/ fncel.2014.00236

Bienvenu T, Chelly J. 2006. Molecular genetics of Rett syndrome: when DNA methylation goes unrecognized. Nat Rev Genet 7: 415-426. doi:10.1038/nrg1878

Buchovecky CM, Turley SD, Brown HM, Kyle SM, McDonald JG, Liu B, Pieper AA, Huang W, Katz DM, Russell DW, et al. 2013. A suppressor screen in Mecp2 mutant mice implicates cholesterol metabolism in Rett syndrome. Nat Genet 45: 1013-1020. doi:10.1038/ng.2714

Carpinelli MR, Hilton DJ, Metcalf D, Antonchuk JL, Hyland CD, Mifsud SL, Di Rago L, Hilton AA, Willson TA, Roberts AW, et al. 2004. Suppressor screen in $\mathrm{Mpl}^{-/-}$mice: $c-M y b$ mutation causes supraphysiological production of platelets in the absence of thrombopoietin signaling. Proc Natl Acad Sci 101: 6553-6558. doi:10.1073/pnas.0401496101

Chao HT, Zoghbi HY, Rosenmund C. 2007. MeCP2 controls excitatory synaptic strength by regulating glutamatergic synapse number. Neuron 56: 58-65. doi:10.1016/j.neuron.2007.08.018

Chen RZ, Akbarian S, Tudor M, Jaenisch R. 2001. Deficiency of methyl-CpG binding protein-2 in CNS neurons results in a Rett-like phenotype in mice. Nat Genet 27: 327-331. doi:10.1038/85906

Chew TG, Peaston A, Lim AK, Lorthongpanich C, Knowles BB, Solter D. 2013. A tudor domain protein SPINDLIN1 interacts with the mRNAbinding protein SERBP1 and is involved in mouse oocyte meiotic resumption. PLoS One 8: e69764. doi:10.1371/journal.pone.0069764

Choi JW, Zhao MH, Liang S, Guo J, Lin ZL, Li YH, Jo YJ, Kim NH, Cui XS. 2017. Spindlin 1 is essential for metaphase II stage maintenance and chromosomal stability in porcine oocytes. Mol Hum Reprod 23: 166176. doi:10.1093/molehr/gax005

Cougnoux A, Drummond RA, Collar AL, Iben JR, Salman A, Westgarth H, Wassif CA, Cawley NX, Farhat NY, Ozato K, et al. 2018. Microglia activation in Niemann-Pick disease, type C1 is amendable to therapeutic intervention. Hum Mol Genet 27: 2076-2089. doi:10.1093/hmg/ddy112

Enikanolaiye A, Justice MJ. 2019. Model systems inform rare disease diagnosis, therapeutic discovery and pre-clinical efficacy. In Emerging topics in life sciences: rare diseases: new therapeutic avenues (ed. A MacKenzie, S Groft, M Justice, C van Karnebeek), Vol. 3, pp. 1-10. Portland Press, London, UK.

Escribano-Díaz C, Orthwein A, Fradet-Turcotte A, Xing M, Young JT, Tkáč J, Cook MA, Rosebrock AP, Munro M, Canny MD, et al. 2013. A cell cycledependent regulatory circuit composed of 53BP1-RIF1 and BRCA1-CtIP controls DNA repair pathway choice. Mol Cell 49: 872-883. doi:10 .1016/j.molcel.2013.01.001

Falck J, Forment JV, Coates J, Mistrik M, Lukas J, Bartek J, Jackson SP. 2012. CDK targeting of NBS1 promotes DNA-end resection, replication restart and homologous recombination. EMBO Rep 13: 561-568. doi:10.1038/ embor.2012.58

Feng J, Xian Q, Guan T, Hu J, Wang M, Huang Y, So KF, Evans SM, Chai G, Goffinet AM, et al. 2016. Celsr3 and Fzd3 organize a pioneer neuron scaffold to steer growing thalamocortical axons. Cereb Cortex 26: 3323-3334. doi:10.1093/cercor/bhw132

Fog CK, Galli GG, Lund AH. 2012. PRDM proteins: important players in differentiation and disease. Bioessays 34: 50-60. doi:10.1002/bies .201100107

Frappart PO, McKinnon PJ. 2008. Mouse models of DNA double-strand break repair and neurological disease. DNA Repair (Amst) 7: 10511060. doi:10.1016/j.dnarep.2008.03.007

Ge C, Che L, Ren J, Pandita RK, Lu J, Li K, Pandita TK, Du C. 2015. BRUCE regulates DNA double-strand break response by promoting USP8 deubiquitination of BRIT1. Proc Natl Acad Sci 112: E1210-E1219. doi:10 $.1073 /$ pnas. 1418335112

Genetic Modifiers of Huntington's Disease (GeM-HD) Consortium. 2019 CAG repeat not polyglutamine length determines timing of Huntington's disease onset. Cell 178: 887-900.e14. doi:10.1016/j.cell 2019.06.036

Gonzales JC, Gordts PL, Foley EM, Esko JD. 2013. Apolipoproteins E and AV mediate lipoprotein clearance by hepatic proteoglycans. J Clin Invest 123: 2742-2751. doi:10.1172/JCI67398

Grillo E, Villard L, Clarke A, Ben Zeev B, Pineda M, Bahi-Buisson N, Hryniewiecka-Jaworska A, Bienvenu T, Armstrong J, Martinez AR, et al. 2012. Rett networked database: an integrated clinical and genetic network of Rett syndrome databases. Hum Mutat 33: 1031-1036. doi:10 1002 /humu. 22072

Guy J, Hendrich B, Holmes M, Martin JE, Bird A. 2001. A mouse Mecp2-null mutation causes neurological symptoms that mimic Rett syndrome. Nat Genet 27: 322-326. doi:10.1038/85899

\section{Genome Research}

www.genome.org 
Haeckel A, Ahuja R, Gundelfinger ED, Qualmann B, Kessels MM. 2008. The actin-binding protein Abp1 controls dendritic spine morphology and is important for spine head and synapse formation. J Neurosci 28: 1003110044. doi:10.1523/JNEUROSCI.0336-08.2008

Hasegawa S, Kume H, Iinuma S, Yamasaki M, Takahashi N, Fukui T. 2012a. Acetoacetyl-CoA synthetase is essential for normal neuronal development. Biochem Biophys Res Commun 427: 398-403. doi:10.1016/j.bbrc .2012 .09 .076

Hasegawa S, Noda K, Maeda A, Matsuoka M, Yamasaki M, Fukui T. 2012b. Acetoacetyl-CoA synthetase, a ketone body-utilizing enzyme, is controlled by SREBP-2 and affects serum cholesterol levels. Mol Genet Metab 107: 553-560. doi:10.1016/j.ymgme.2012.08.017

Heckman LD, Chahrour MH, Zoghbi HY. 2014. Rett-causing mutations reveal two domains critical for MeCP2 function and for toxicity in MECP2 duplication syndrome mice. eLife 3: e02676. doi:10.7554/eLife.02676

Hitotsumachi S, Carpenter DA, Russell WL. 1985. Dose-repetition increases the mutagenic effectiveness of $\mathrm{N}$-ethyl- $\mathrm{N}$-nitrosourea in mouse spermatogonia. Proc Natl Acad Sci 82: 6619-6621. doi:10.1073/pnas.82.19 .6619

Hohenauer T, Moore AW. 2012. The Prdm family: expanding roles in stem cells and development. Development 139: 2267-2282. doi:10.1242/dev .070110

Huertas P. 2010. DNA resection in eukaryotes: deciding how to fix the break. Nat Struct Mol Biol 17: 11-16. doi:10.1038/nsmb.1710

Hwang JY, Zukin RS. 2018. REST, a master transcriptional regulator in neurodegenerative disease. Curr Opin Neurobiol 48: 193-200. doi:10.1016/j .conb.2017.12.008

Jackson CH. 2016. flexsurv: a platform for parametric survival modeling in R. J Stat Softw 70: i08. doi:10.18637/jss.v070.i08

Jellinger K, Seitelberger F. 1986. Neuropathology of Rett syndrome. Am J Med Genet Suppl 25: 259-288. doi:10.1002/ajmg.1320250528

Justice MJ, Buchovecky CM, Kyle SM, Djukic A. 2013. A role for metabolism in Rett syndrome pathogenesis: new clinical findings and potential treatment targets. Rare Dis 1: e27265. doi:10.4161/rdis.27265

Katz DM, Berger-Sweeney JE, Eubanks JH, Justice MJ, Neul JL, Pozzo-Miller L, Blue ME, Christian D, Crawley JN, Giustetto M, et al. 2012. Preclinical research in Rett syndrome: setting the foundation for translational success. Dis Model Mech 5: 733-745. doi:10.1242/dmm.011007

Kile BT, Hentges KE, Clark AT, Nakamura H, Salinger AP, Liu B, Box N, Stockton DW, Johnson RL, Behringer RR, et al. 2003. Functional genetic analysis of mouse chromosome 11. Nature 425: 81-86. doi:10.1038/ nature01865

Knutson SK, Chyla BJ, Amann JM, Bhaskara S, Huppert SS, Hiebert SW. 2008. Liver-specific deletion of histone deacetylase 3 disrupts metabolic transcriptional networks. EMBO J 27: 1017-1028. doi:10.1038/emboj .2008 .51

Kyle SM, Saha PK, Brown HM, Chan LC, Justice MJ. 2016. MeCP2 co-ordinates liver lipid metabolism with the NCoR1/HDAC3 corepressor complex. Hum Mol Genet 25: 3029-3041. doi:10.1093/hmg/ddw15

Kyle SM, Vashi N, Justice MJ. 2018. Rett syndrome: a neurological disorder with metabolic components. Open Biol 8: 170216. doi:10.1098/rsob .170216

Li H, Durbin R. 2010. Fast and accurate long-read alignment with BurrowsWheeler transform. Bioinformatics 26: 589-595. doi:10.1093/bioinfor matics/btp698

Li H, Handsaker B, Wysoker A, Fennell T, Ruan J, Homer N, Marth G, Abecasis G, Durbin R; 1000 Genome Project Data Processing Subgroup. 2009. The Sequence Alignment/Map format and SAMtools. Bioinformatics 25: 2078-2079. doi:10.1093/bioinformatics/btp352

Lotz K, Pyrowolakis G, Jentsch S. 2004. BRUCE, a giant E2/E3 ubiquitin ligase and inhibitor of apoptosis protein of the trans-Golgi network, is required for normal placenta development and mouse survival. Mol Cell Biol 24: 9339-9350. doi:10.1128/MCB.24.21.9339-9350.2004

Lund EG, Xie C, Kotti T, Turley SD, Dietschy JM, Russell DW. 2003. Knockout of the cholesterol 24-hydroxylase gene in mice reveals a brain-specific mechanism of cholesterol turnover. J Biol Chem 278: 22980-22988. doi:10.1074/jbc.M303415200

Lyst MJ, Ekiert R, Ebert DH, Merusi C, Nowak J, Selfridge J, Guy J, Kastan NR, Robinson ND, de Lima Alves F, et al. 2013. Rett syndrome mutations abolish the interaction of MeCP2 with the NCoR/SMRT co-repressor. Nat Neurosci 16: 898-902. doi:10.1038/nn.3434

Madabhushi R, Pan L, Tsai LH. 2014. DNA damage and its links to neurodegeneration. Neuron 83: 266-282. doi:10.1016/j.neuron.2014.06.034

Madabhushi R, Gao F, Pfenning AR, Pan L, Yamakawa S, Seo J, Rueda R, Phan TX, Yamakawa H, Pao PC, et al. 2015. Activity-induced DNA breaks govern the expression of neuronal early-response genes. Cell 161: $1592-1605$. doi:10.1016/j.cell.2015.05.032

Makharashvili N, Tubbs AT, Yang SH, Wang H, Barton O, Zhou Y, Deshpande RA, Lee JH, Lobrich M, Sleckman BP, et al. 2014. Catalytic and noncatalytic roles of the CtIP endonuclease in double-strand break end resection. Mol Cell 54: 1022-1033. doi:10.1016/j.molcel.2014.04 .011

Mandel G, Fiondella CG, Covey MV, Lu DD, Loturco JJ, Ballas N. 2011. Repressor element 1 silencing transcription factor (REST) controls radial migration and temporal neuronal specification during neocortical development. Proc Natl Acad Sci 108: 16789-16794. doi:10.1073/pnas 1113486108

Margolis SS, Salogiannis J, Lipton DM, Mandel-Brehm C, Wills ZP, Mardinly AR, Hu L, Greer PL, Bikoff JB, Ho HY, et al. 2010. EphB-mediated degradation of the RhoA GEF Ephexin5 relieves a developmental brake on excitatory synapse formation. Cell 143: 442-455. doi:10.1016/j.cell.2010 .09 .038

Matera I, Watkins-Chow DE, Loftus SK, Hou L, Incao A, Silver DL, Rivas C, Elliott EC, Baxter LL, Pavan WJ. 2008. A sensitized mutagenesis screen identifies Gli3 as a modifier of Sox10 neurocristopathy. Hum Mol Genet 17: 2118-2131. doi:10.1093/hmg/ddn110

Merlo D, Mollinari C, Racaniello M, Garaci E, Cardinale A. 2016. DNA double strand breaks: a common theme in neurodegenerative diseases. Curr Alzheimer Res 13: 1208-1218. doi:10.2174/15672050136661604 01114915

Mi W, Zhang Y, Lyu J, Wang X, Tong O, Peng D, Xue Y, Tencer AH, Wen $\mathrm{H}_{\text {, }}$ $\mathrm{Li} \mathrm{W}$, et al. 2018. The ZZ-type zinc finger of ZZZ3 modulates the ATAC complex-mediated histone acetylation and gene activation. Nat Commun 9: 3759. doi:10.1038/s41467-018-06247-5

Mobley AS, Miller AM, Araneda RC, Maurer LR, Muller F, Greer CA. 2010. Hyperpolarization-activated cyclic nucleotide-gated channels in olfactory sensory neurons regulate axon extension and glomerular formation. J Neurosci 30: 16498-16508. doi:10.1523/JNEUROSCI.4225-10 .2010

Monaghan CE, Nechiporuk T, Jeng S, McWeeney SK, Wang J, Rosenfeld MG, Mandel G. 2017. REST corepressors RCOR1 and RCOR2 and the repressor INSM1 regulate the proliferation-differentiation balance in the developing brain. Proc Natl Acad Sci 114: E406-E415. doi:10.1073/pnas 1620230114

Moran JL, Bolton AD, Tran PV, Brown A, Dwyer ND, Manning DK, Bjork BC, Li C, Montgomery K, Siepka SM, et al. 2006. Utilization of a whole genome SNP panel for efficient genetic mapping in the mouse. Genome Res 16: 436-440. doi:10.1101/gr.4563306

Morris JH, Apeltsin L, Newman AM, Baumbach J, Wittkop T, Su G, Bader GD, Ferrin TE. 2011. clusterMaker: a multi-algorithm clustering plugin for Cytoscape. BMC Bioinformatics 12: 436. doi:10.1186/1471-2105$12-436$

Mottis A, Mouchiroud L, Auwerx J. 2013. Emerging roles of the corepressors NCoR1 and SMRT in homeostasis. Genes Dev 27: 819-835. doi:10.1101/ gad.214023.113

Muotri AR, Marchetto MC, Coufal NG, Oefner R, Yeo G, Nakashima K, Gage FH. 2010. L1 retrotransposition in neurons is modulated by MeCP2. Nature 468: 443-446. doi:10.1038/nature09544

Mzoughi S, Zhang J, Hequet D, Teo SX, Fang H, Xing QR, Bezzi M, Seah MKY, Ong SLM, Shin EM, et al. 2017. PRDM15 safeguards naive pluripotency by transcriptionally regulating WNT and MAPK-ERK signaling. Nat Genet 49: 1354-1363. doi:10.1038/ng.3922

Neuhaus IM, Beier DR. 1998. Efficient localization of mutations by interval haplotype analysis. Mamm Genome 9: 150-154. doi:10.1007/ s003359900706

Neul JL, Zoghbi HY. 2004. Rett syndrome: a prototypical neurodevelopmental disorder. Neuroscientist 10: 118-128. doi:10.1177/107385 8403260995

Orthwein A, Noordermeer SM, Wilson MD, Landry S, Enchev RI, Sherker A Munro M, Pinder J, Salsman J, Dellaire G, et al. 2015. A mechanism for the suppression of homologous recombination in G1 cells. Nature 528: 422-426. doi:10.1038/nature16142

Paterson JK, Renkema K, Burden L, Halleck MS, Schlegel RA, Williamson P, Daleke DL. 2006. Lipid specific activation of the murine $\mathrm{P}_{4}$-ATPase Atp8a1 (ATPase II). Biochemistry 45: 5367-5376. doi:10.1021/ bi052359b

Pluvinage JV, Haney MS, Smith BAH, Sun J, Iram T, Bonanno L, Li L, Lee DP, Morgens DW, Yang AC, et al. 2019. CD22 blockade restores homeostatic microglial phagocytosis in ageing brains. Nature 568: 187-192. doi:10 .1038/s41586-019-1088-4

Ravn K, Roende G, Duno M, Fuglsang K, Eiklid KL, Tümer Z, Nielsen JB, Skjeldal OH. 2011. Two new Rett syndrome families and review of the literature: expanding the knowledge of MECP2 frameshift mutations. Orphanet J Rare Dis 6: 58. doi:10.1186/1750-1172-6-58

$\mathrm{R}$ Core Team. 2019. R: a language and environment for statistical computing. $\mathrm{R}$ Foundation for Statistical Computing, Vienna. http://www.R-project .org/.

Ren J, Shi M, Liu R, Yang QH, Johnson T, Skarnes WC, Du C. 2005. The Birc6 (Bruce) gene regulates p53 and the mitochondrial pathway of apoptosis and is essential for mouse embryonic development. Proc Natl Acad Sci 102: 565-570. doi:10.1073/pnas.0408744102 
Ross PD, Guy J, Selfridge J, Kamal B, Bahey N, Tanner KE, Gillingwater TH, Jones RA, Loughrey CM, McCarroll CS, et al. 2016. Exclusive expression of MeCP2 in the nervous system distinguishes between brain and peripheral Rett syndrome-like phenotypes. Hum Mol Genet 25: 43894404. doi:10.1093/hmg/ddw269

Sankar A, Kooistra SM, Gonzalez JM, Ohlsson C, Poutanen M, Helin K. 2017. Maternal expression of the histone demethylase $\mathrm{Kdm} 4 \mathrm{a}$ is crucial for pre-implantation development. Development 144: 3264-3277. doi:10.1242/dev.155473

Segatto M, Trapani L, Di Tunno I, Sticozzi C, Valacchi G, Hayek J, Pallottini V. 2014. Cholesterol metabolism is altered in Rett syndrome: a study on plasma and primary cultured fibroblasts derived from patients. PLoS One 9: e104834. doi:10.1371/journal.pone.0104834

Shahbazian MD, Sun Y, Zoghbi HY. 2002. Balanced X chromosome inactivation patterns in the Rett syndrome brain. Am J Med Genet 111: 164168. doi:10.1002/ajmg.10557

Shanle EK, Shinsky SA, Bridgers JB, Bae N, Sagum C, Krajewski K, Rothbart SB, Bedford MT, Strahl BD. 2017. Histone peptide microarray screen of chromo and Tudor domains defines new histone lysine methylation interactions. Epigenetics Chromatin 10: 12. doi:10.1186/s13072-0170117-5

Shannon P, Markiel A, Ozier O, Baliga NS, Wang JT, Ramage D, Amin N, Schwikowski B, Ideker T. 2003. Cytoscape: a software environment for integrated models of biomolecular interaction networks. Genome Res 13: 2498-2504. doi:10.1101/gr.1239303

Shepherd GM, Katz DM. 2011. Synaptic microcircuit dysfunction in genetic models of neurodevelopmental disorders: focus on Mecp2 and Met. Cur Opin Neurobiol 21: 827-833. doi:10.1016/j.conb.2011.06.006

Squillaro T, Alessio N, Cipollaro M, Renieri A, Giordano A, Galderisi U. 2010. Partial silencing of methyl cytosine protein binding 2 (MECP2) in mesenchymal stem cells induces senescence with an increase in damaged DNA. FASEB J 24: 1593-1603. doi:10.1096/fj.09-143057

Suberbielle E, Sanchez PE, Kravitz AV, Wang X, Ho K, Eilertson K, Devidze N, Kreitzer AC, Mucke L. 2013. Physiologic brain activity causes DNA double-strand breaks in neurons, with exacerbation by amyloid- $\beta$. Nat Neurosci 16: 613-621. doi:10.1038/nn.3356

Thakar S, Wang L, Yu T, Ye M, Onishi K, Scott J, Qi J, Fernandes C, Han X, Yates JR III, et al. 2017. Evidence for opposing roles of Celsr3 and Vangl2 in glutamatergic synapse formation. Proc Natl Acad Sci 114: E610-E618. doi:10.1073/pnas.1612062114

Tomberg K, Westrick RJ, Kotnik EN, Cleuren AC, Siemieniak DR, Zhu G, Saunders TL, Ginsburg D. 2018. Whole exome sequencing of ENU-induced thrombosis modifier mutations in the mouse. PLoS Genet 14: e1007658. doi:10.1371/journal.pgen.1007658

Wang F, Wang Q, Li C, Yu P, Qu Y, Zhou L. 2017. The role of Celsr3 in the development of central somatosensory projections from dorsal root ganglia. Neuroscience 359: 267-276. doi:10.1016/j.neuroscience.2017 .07 .040

Warde-Farley D, Donaldson SL, Comes O, Zuberi K, Badrawi R, Chao P, Franz M, Grouios C, Kazi F, Lopes CT, et al. 2010. The GeneMANIA prediction server: biological network integration for gene prioritization and predicting gene function. Nucleic Acids Res 38: W214-W220. doi:10 .1093/nar/gkq537

Weber AR, Krawczyk C, Robertson AB, Kuśnierczyk A, Vågbø $\mathrm{CB}$, Schuermann D, Klungland A, Schär P. 2016. Biochemical reconstitution of TET1-TDG-BER-dependent active DNA demethylation reveals a highly coordinated mechanism. Nat Commun 7: 10806. doi:10.1038/ ncomms10806

Westrick RJ, Tomberg K, Siebert AE, Zhu G, Winn ME, Dobies SL, Manning SL, Brake MA, Cleuren AC, Hobbs LM, et al. 2017. Sensitized mutagenesis screen in Factor V Leiden mice identifies thrombosis suppressor loci. Proc Natl Acad Sci 114: 9659-9664. doi:10.1073/pnas.1705762114

Xu X, Miller EC, Pozzo-Miller L. 2014. Dendritic spine dysgenesis in Rett syndrome. Front Neuroanat 8: 97. doi:10.3389/fnana.2014.00097

Yang J, Guo R, Wang H, Ye X, Zhou Z, Dan J, Wang H, Gong P, Deng W, Yin $\mathrm{Y}$, et al. 2016. Tet enzymes regulate telomere maintenance and chromosomal stability of mouse ESCs. Cell Rep 15: 1809-1821. doi:10.1016/j .celrep.2016.04.058

Zhou J, Wang F, Xu C, Zhou Z, Zhang W. 2017. The histone demethylase JMJD2A regulates the expression of BDNF and mediates neuropathic pain in mice. Exp Cell Res 361: 155-162. doi:10.1016/j.yexcr.2017.10 .014

Received October 18, 2019; accepted in revised form March 20, 2020.

\section{Genome Research}

www.genome.org 


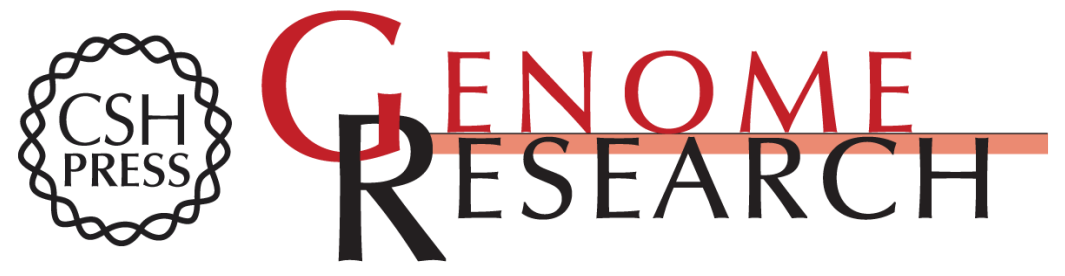

\section{Suppressor mutations in Mecp2-null mice implicate the DNA damage response in Rett syndrome pathology}

Adebola Enikanolaiye, Julie Ruston, Rong Zeng, et al.

Genome Res. 2020 30: 540-552 originally published online April 21, 2020

Access the most recent version at doi:10.1101/gr.258400.119

\section{Supplemental} Material

References

Open Access

Creative Commons

License

Email Alerting Service
http://genome.cshlp.org/content/suppl/2020/04/21/gr.258400.119.DC1

This article cites 87 articles, 20 of which can be accessed free at: http://genome.cshlp.org/content/30/4/540.full.html\#ref-list-1

Freely available online through the Genome Research Open Access option.

This article, published in Genome Research, is available under a Creative Commons License (Attribution 4.0 International), as described at http://creativecommons.org/licenses/by/4.0/.

Receive free email alerts when new articles cite this article - sign up in the box at the top right corner of the article or click here.

\section{Affordable, Accurate Sequencing.}

To subscribe to Genome Research go to:

https://genome.cshlp.org/subscriptions

(C) 2020 Enikanolaiye et al.; Published by Cold Spring Harbor Laboratory Press 